\title{
Residential Demand Response Strategies and Applications in Active Distribution Network Management
}

\author{
Sima Davarzani ${ }^{1}{ }^{*}$, Ioana Pisica ${ }^{2}$, Gareth A. Taylor ${ }^{2}$, Kevin J. Munisami ${ }^{3}$ \\ ${ }^{1}$ Smart Grid Development, Asset Management, UK Power Networks, London, SE1 6NP \\ ${ }^{2}$ Brunel Institute of Energy Future, Brunel University London, Uxbridge, UB8 3PH \\ ${ }^{3}$ School of Computing and Engineering, University of West London, Ealing, W5 5RF
}

\begin{abstract}
Electricity distribution is moving towards active, more flexible, smarter and decentralized energy systems. This transition requires System Operators (SO) to dynamically monitor and control the power flow across the network. Demand Response (DR) can be considered as an alternative solution to the costly investment of upgrading conventional Distribution Networks (DN). Hence, the role of DR as a considerable potential of elastic demands in the Active Distribution Network Management (ADNM) is vital. The aim of this paper is to review the recent literature and pilot implementations towards residential DR activation and applications at the electricity distribution level. Background concepts, DR programmes and key participants in ADNM are explained. DR activation strategies for residential demand responsiveness at the network level are categorized and discussed together with the challenges and future directions of this technology. The most relevant DR innovation trials in Great Britain (GB) and their outcomes are also discussed.
\end{abstract}

\section{HIGHLIGHTS}

- Review of residential Demand Response for distribution network management

- Classification based on strategies, applications and network constraints

- Analysis of the most relevant innovation trials in Great Britain

- Discussion of barriers, challenges and future direction in the implementation of residential Demand Response

Word count: 11530

\section{KEYWORDS}

Residential demand response, distribution network, flexible demand, active distribution network management.

\section{ABBREVIATIONS}

$\begin{array}{llll}\text { ADNM } & \text { Active Distribution Network Management } & \text { FES } & \text { Flexibility Energy Scheme } \\ \text { DER } & \text { Distributed Energy Resource } & \text { HEMS } & \text { Home Energy Management System } \\ \text { DR } & \text { Demand Response } & \text { LV } & \text { Low Voltage } \\ \text { DLC } & \text { Direct Load Control } & \text { MV } & \text { Medium Voltage } \\ \text { DN } & \text { Distribution Network } & \text { RTP } & \text { Real-Time Pricing } \\ \text { DNO } & \text { Distribution Network Operator } & \text { RDRA } & \text { Residential Demand Response } \\ & & & \text { Aggregator } \\ \text { DSO } & \text { Distribution System Operator } & \text { SO } & \text { System Operator } \\ \text { dToU } & \text { Dynamic Time-of-Use } & \text { ToU } & \text { Time-of-Use }\end{array}$




\section{Introduction}

The Climate Change Act (CCA) 2008 made the United Kingdom (UK) the first country to introduce long-term, legally-binding targets to mitigate climate change [1]. The CCA also prompted many countries thereafter to review their environmental policies and this resulted in the creation of worldwide legally binding 'carbon budgets'. By 2016, 189 countries had become a party of the United Nations Framework Convention on Climate Change (UNFCCC) to adopt strategies and regulations for achieving net-zero emission target. To date, five more countries, Sweden, France, Denmark, Hungry and New Zealand have also set carbon-budgets into law, while others, Spain, Chile and Fiji have proposed legislations [2].

In GB, the target of this proposed legislation was the reduction of carbon dioxide emission by a minimum of $27 \%$ by 2020 , a reduction of $90 \%$ in the carbon intensity from energy generation by 2030 [3] as well as final target of $80 \%$ for 2050 [4]. Along with deploying clean energy technologies, there is also a great requirement for improving the energy usage efficiency [5], i.e., using less energy to deliver the same service. On the other hand, the change in the load shapes due to the introduction and growth of new loads in the network introduced a new challenge faced by the future networks. DR can provide an intelligent way of managing efficiently electricity demand and supply from decentralized energy sources [6].

An analysis from Guidehouse Insights (former Navigant) predicted triple growth in the global residential DR capacity from 2019 baseline to reach to $47.4 \mathrm{GW}$ by the end of 2028 [7]. After North America, where DR has been implemented widely for decades, Europe is next in line with GB being the first country to open various DR markets to consumers [8]. A UK energy consumption analysis [9] reported that the $46 \%$ increase in the number of households and the $17 \%$ population growth since 1970 have drastically changed the total domestic electricity consumption. Therefore in spite of improvement in the efficiency of home appliances, their frequency usage, cyclic length as well as energy consumption are still rising [10]. With expected dramatic rise in Heat Pumps (HP) and Electric Vehicles (EV) by 2050 [11-12], the load demand as well as the number of voltage violations will also rise [13], thus causing concerns for Distribution Network Operators (DNO). The adverse effects of integrating these new loads can be alleviated through DR by optimizing their operation time [14].

Advancements in automated infrastructure and technology in DN have enabled residential consumers to participate in demand curtailment plans as reviewed by Haider et al [15]. Optimization-based home energy management algorithms have recently been developed for DR activation of prosumers. The objective of these systems is to find the optimal consumption schedule for consumers considering various factors such as their consumption profiles, energy cost and environmental concerns. Comprehensive literature reviews have been conducted in this area where factors such as DR programmes, optimization techniques and smart technologies have been considered [16-23]. In a more advanced approach, Antonopoulos et al. [24] have provided a comprehensive systematic review on applying Artificial Intelligence (AI) and Machine Learning (ML) techniques to Home Energy Management Systems (HEMS) and network optimization by predicting the available DR capacity and price adjustment. Their analysis shows that after game theory and mechanism design techniques, the majority of researches applied AI at residential level.

There is a need for smart solutions to minimize the cost of the DN to accommodate the previously mentioned changes in the electricity consumption pattern and integration of more decentralized flexible generators. This has driven the typical managing functionalities of DNOs to now shift to Distribution System Operators (DSOs) with a 
view to ensuring a smarter and active network [25-26]. This transformation is also aligned with netzero decarbonization policies [27]. The characteristics and challenges in this transition to DSO are depicted in Figure 1. The future role of a DSO should consider improving the engagement of electricity users to provide real-time flexibilities in support of local demand-supply balancing and system optimization. DR as an alternative and innovative solution necessitates customers' awareness of opportunities to participate in available programmes [28].

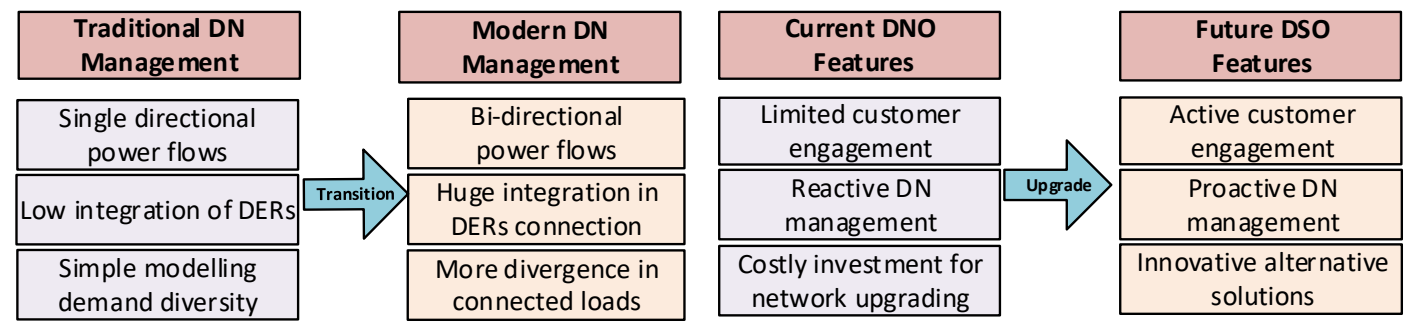

\begin{tabular}{|c|c|c|}
\hline \multicolumn{3}{|c|}{ Alternative Solution } \\
\hline Non-dispatchable resourc & Transformation & Dispatchable resources (DSO) \\
\hline \multicolumn{3}{|c|}{ Demand Resposne } \\
\hline \multicolumn{2}{|c|}{ DR Enabled Tools } & DR Challenges \\
\hline Infrastructure/ Technology & Flexible Demand & Customer Engagement \\
\hline Flexible tariffs, Incentives & Energy storage & Education \\
\hline Advanced smart meter & Smart appliances & Awareness \\
\hline Home energy management & Air conditioning & Motivation \\
\hline DG and storage system & Heat pumps & Comfort Level \\
\hline Smart appliance control node & Electrical vehicles & Behaviour unpredictability \\
\hline Communication infrastructure & Local generation & Loyalty \\
\hline
\end{tabular}

Figure 1. DNO to DSO transformation - features, challenges and the DR as an alternative solution [29]

Many approaches have been used in reviewing DR, using various categorization strategies. A thorough review of DR in smart grid in [30] shows the advantages of DR in reducing peak load and in enhancing reliability. Kang et al [31] confirmed the same benefits of DR but using an economic approach and with the use of energy storage. The application of DR has also been extended to microgrids and this has been extensively reviewed in [32]. They concluded that the simulation results may not be practical due to the simplicity of modeling the microgrids parameters as well as the assumptions of customers' willingness towards participating in DR. However, these findings could be used as the baseline for further work for real implementation.

A meta-analysis of 32 residential DR programmes by Srivasta et al [33] concluded that there is a direct correlation between the success of the programmes with geography of urbanization, the energy policies and regulations, and the economic development. A review of international DR implementation [34] shows the adoption of DR programmes are being pursued globally due to their advantages to all participants especially with the increase in the use of renewable sources. Other studies [35-36] identified and analyzed the DR barriers for price-base DR and direct load control. The main barriers for both consumers and DSOs are uncertainties in benefits and limited deployment of appliance control technologies such as HEMS. 
Accessing the right data to accurately model the demand profile is a key enabler in order to manage the DR effectively. Consequently the European Union's Third Energy Package legislation proposed in 2007 required European states to rollout, where economically viable, electricity smart meters to $80 \%$ of households by 2020 [37]. Smart meters provide a two-way communication interface between customers, DSOs and suppliers [38]. This will enable the introduction and employment of more dynamic electricity tariffs and improve low voltage (LV) networks monitoring, thus leading future DSOs to gain additional roles [39]. A comprehensive review on smart meter data analytics [40] specified three key applications of these data on DR programmes: load analysis, load forecasting and load management.

The importance of such data has triggered a significant interest in recent researches to employ data-driven approaches, AI and machine-learning enabled analysis to evaluate DR capacity. Numerous literature focus on applying these techniques to extract and analyze the information from real-time smart meter readings, historical data, weather forecasting, etc. The typical applications of these techniques consist of generating a bunch of clusters of households with homogeneous characteristics patterns using supervised machine learning techniques [41-43]. For extracting consumption patterns, unsupervised learning techniques [44-45] have been a preferred approach while for efficiency ranking, non-parametric data-driven method [46-48] have been utilized. Other applications model the endusers energy load profile using data-driven approach [49-53] and AI/machine learning techniques [54-60] to predict the potential quantity of available flexibility from end-users under various DR schemes and price variations. In advanced and smart grid systems, these techniques merge the data into the network or price optimization models to adjust the network control policy or market strategies with the aim of balancing constraints management and demandsupply [61-66].

These new technologies together with advancements in infrastructure such as Internet of Things (IoT) [67] and local generations, have enabled the emergence of a new energy platform, Peer to Peer (P2P) energy. A report by Sia Partners [68] states that peer to peer energy trading community can result in reduction of up to $11 \%$ in consumers energy bill and nearly $2 \%$ profit from their Photovoltaic (PV) generation. Recent studies [69-72] proposed a P2P energy market platform to coordinate DR in a decentralized way with some focus on LV grid connected Microgrids [73-77] and Nanogrids [78]. An evaluation of P2P mechanisms in the GB electricity network by Zhou et. al. [79] concluded a potential economic and technical benefit for consumers. In a proposed P2P energy sharing framework [80], three different models are introduced: bill sharing (BS), mid-market rate (MMR) and auction-based pricing strategy (APS). In the former, the trading price among participants is calculated based on the consumption and production of each consumer within the community, while the price is set by the retailer in MMR based on community's demand and generation. On the other hand, in APS energy trading is done through an auction-based system.

\subsection{Scope of the paper}

Based on the technical review papers studied, DR implementation has either been investigated on its general effect in reducing peak demand or improving the system reliability. However, there are no in-depth analyses of what constraints can be managed across different levels of the DN through residential DR. Hence, the purpose of this paper is to investigate and review the activation strategies and resources, development and performance of the residential DR from the network's perspective. The main contributions of this review compared to the existing ones are that it: 
- Discusses the existing DR applications and solutions from network perspective as a direction for DSOs to maximize the usage of available flexibility in the network.

- Investigates and categorizes the applications and impact of residential DR in managing different constraints in the DN at different voltage levels considering different solution designs and frameworks as a guideline for researches and industry practitioners in the field

- Provides a state-of the art review and categorization of the residential DR innovation pilots in GB projects as a beneficial guideline for future network planning studies

- Identifies the processes, requirements, capabilities and challenges involved in the effective and widely utilization of flexible low-voltage loads in optimizing the DN as a path to future research direction

\subsection{Literature Search Strategy}

The methodology adopted for searching for relevant materials for this review paper is depicted in Figure 2. A combination of two of the largest databases of peer reviewed publications, Scopus and IEEE Explore, was the main tools utilized. These were the most relevant search engines on DR and related topics, with materials published in an array of different journals. The main keywords used were:

- $\quad$ 'Demand Response’ AND ‘Active Distribution Network Management'

- 'Flexible Demand' AND 'Distribution Network'

- 'Optimization' AND 'Distribution Network'

- 'Demand Response AND ‘Aggregators'

The broad number of results returned from these queries were scrutinized and filtered. All papers cited in this work are related to residential DR and network management.
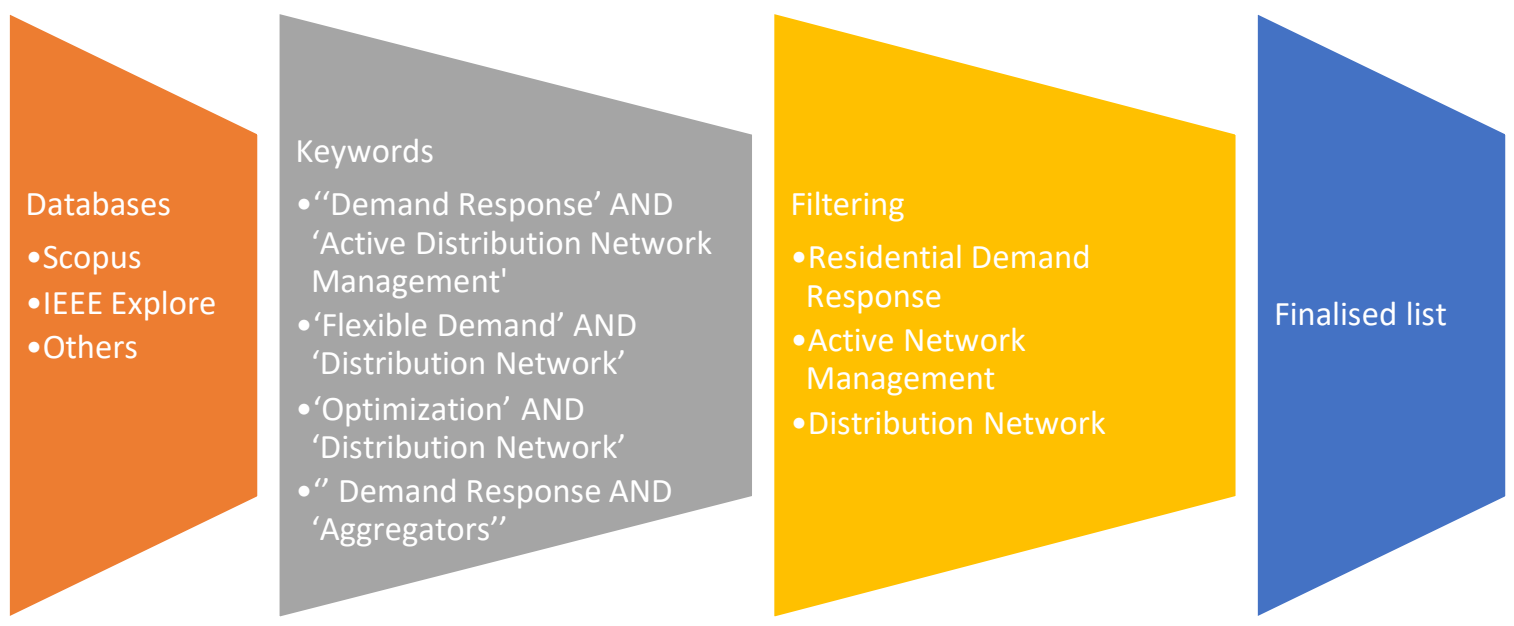

Figure 2. Literature search strategy

A total of 226 publications were reviewed for this paper, mostly from 2010 onwards. While there has been a low number of publications prior to 2011, a rapid increase is observed from 2012 to 2020 . This result is very much in line with the increase in worldwide activity in DR around that period. 


\subsection{Structure of the paper}

We identified the processes involved in the implementation of DR for DN constraints management. A breakdown of this hierarchical structure is shown in Figure 3 and this paper is developed around this structure. For clarification, it is worth mentioning that this categorization started as a basic outline for the paper but was later developed fully with progress in reviewing and analyzing the literature. Chapter 2 gives a classification of DR mechanisms. Key participants and their interactions in the energy network are explained in chapter 3. The objectives of the DR controllers are reviewed in terms of both economic and technical targets in chapter 4. DR frameworks and applications in managing various constraints in the DN are presented in the chapter 5 and 6 respectively. Chapter 7 provides a brief overview of the DR strategies in microgrids. Chapter 8 summarizes the most relevant pilots implemented in GB. Chapter 9 tackles the main challenges and future directions in DR implementation at residential level and is followed by a conclusion.

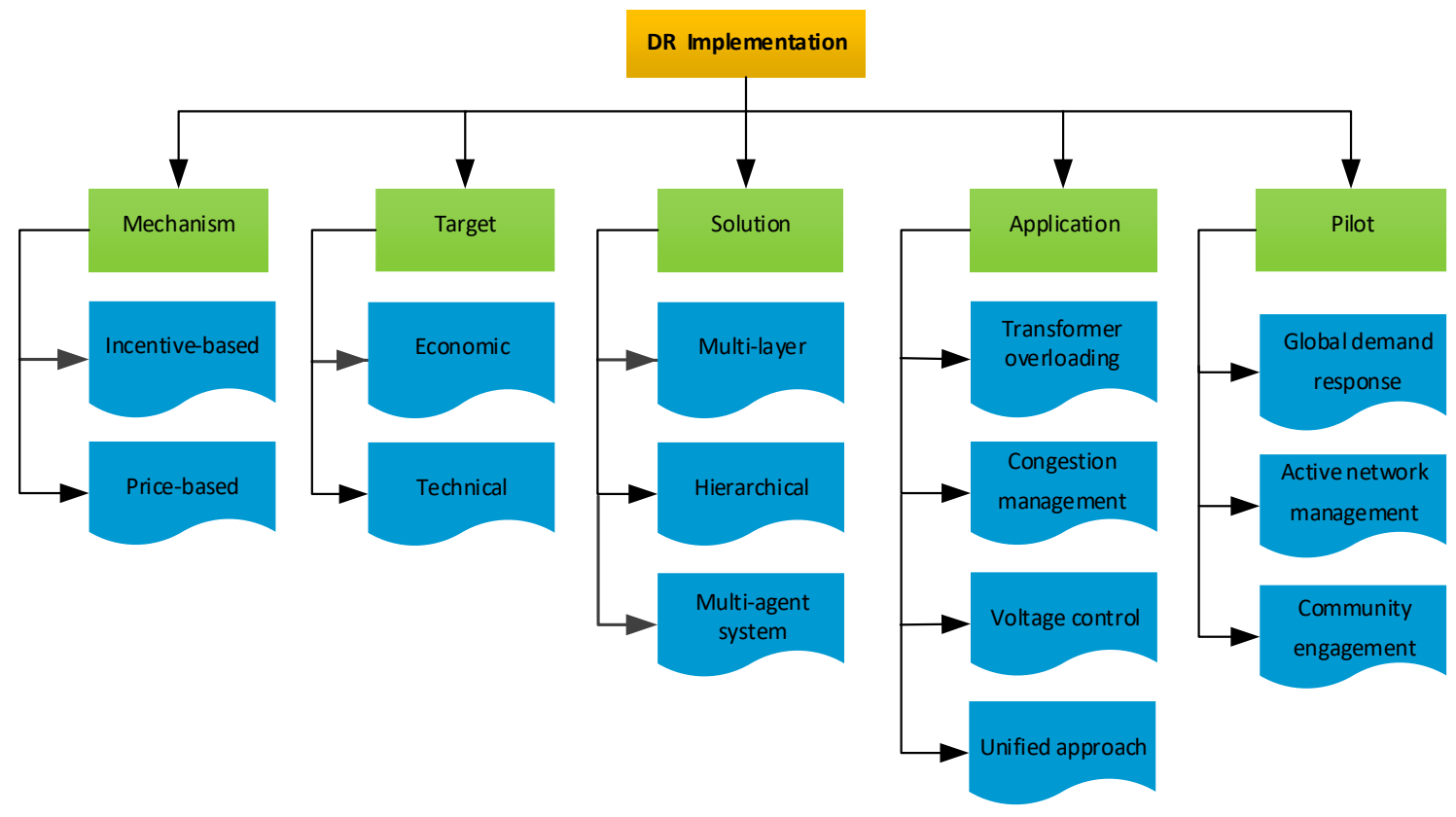

Figure 3. Classification of DR implementation reviewed

\section{Classification of Demand Response Mechanisms}

The two main categories of DR programmes are incentive-based and price-based. The former provides consumers with predefined incentives for their participation in DR schemes, especially during system stress conditions. In pricebased DR, tariffs offered to consumers vary at different times during the day. This type of scheme is usually more suitable for the residential market while the incentive-based ones are more appropriate for larger customers or aggregated demands [81]. Figure 4 shows the classification and differentiation of various DR programmes which are discussed in the next sub-section. The concept behind this classification is further developed in the following section. 


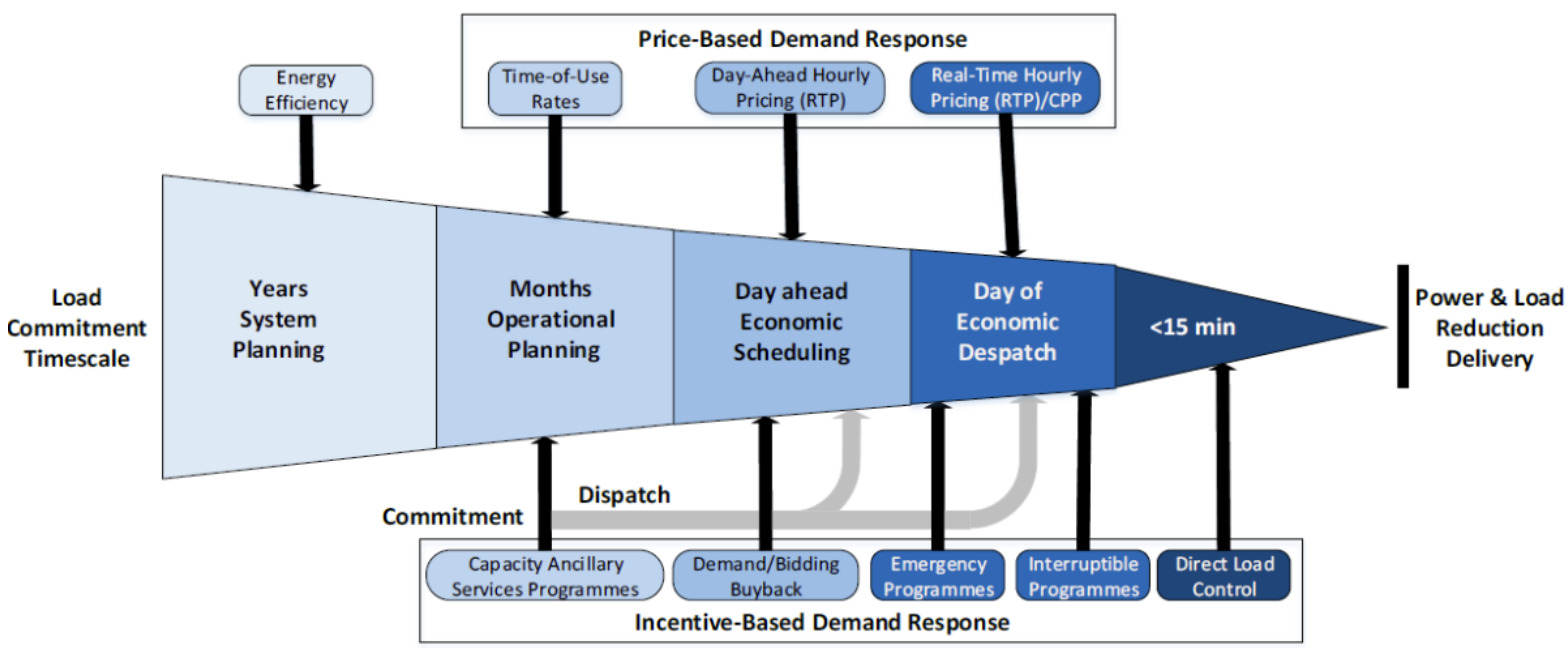

Figure 4. Classification of demand response programmes [82]

\subsection{Incentive-Based Programmes}

Direct Load Control ( $D L C)$ is a programme where SOs are given remote access to customers' equipment to control systems or local reliability contingencies. One example is the "Shetland Northern Isles New Energy Solutions (NINES)" project which was trialed in GB to control electric storage heaters during network emergency conditions or peak load periods [83].

Interruptible/Curtailed (I/C) Load programmes consist of operators requesting customers for pre-defined load curtailment and where non-responders are penalized [84]. Since the residential loads are normally considered as aggregated loads, this facilitates the operator's communication and management.

Demand Bidding/Buyback (DB) programmes give consumers the opportunity to participate in the electricity market by bidding for specific load curtailment [85]. They are run in short periods such as hour or day ahead and are seen as low risk for consumers.

Capacity Markets (CM) programmes involve participants pledging to provide defined load curtailment and they may get penalties for non-compliance. These programmes normally run over medium to long time periods. This scheme was recently implemented in GB where bids are made from the combination of DR (including embedded generation and storage) and existing generation capacity [86].

Ancillary Service Markets (ASM) programmes provide reserve services based on the extent and timeliness of consumers' responses [87]. Their participants are predominantly large and regular energy consumers.

Emergency Demand Response (EDR) programmes are voluntary schemes where pre-defined incentives are offered to customers for their demand curtailment during reliability events [88]. Non-compliance does not result in penalties.

\subsection{Price-Based Programmes}

Fixed pricing is the traditional pricing system with constant price over specific periods e.g., season or year. Electricity bill reduction in this case is only possible by lower consumption.

Time-of-Use (ToU) are pre-determined rates for specific time periods during the day or week. Customers are informed of these tariffs days or even months ahead. Generally, ToU tariffs are higher during peak times as they 
reflect the mean price of wholesale market. For instance, the ToU tariff known as the Economy 7, was introduced to residential customers in GB in 1978 with different pricing bands for day and night [89].

Dynamic Time-of-Use (dToU) rates have a shorter notification period for prices, typically one hour ahead or less. However, although prices can be closer to the actual tariff, there is the possibility of delayed responses due to customers losing foresight. The potential of this kind of tariff in providing DR was investigated in the Low Carbon London (LCL) trial [90]. This pilot resulted in bill reduction in $85 \%$ of households.

Critical Peak Pricing (CPP) consists of rates during critical peaks and these are normally higher than average

ToU rates. Since more customers are engaged, the reliability of the system is enhanced thus leading to higher demand curtailment [91].

Real-Time Pricing (RTP) offers a dynamically changing tariff reflecting the real price of wholesale market. This is based on uniform time steps, e.g. hourly or day ahead, thus allowing customers to alter their consumption to their benefit. A Day-Ahead RTP (DA-RTP) [92] is an alternative RTP where the electricity price is predicated and announced to the customers in a day-ahead basis.

Vickrey-Clarke-Groves (VCG) is a centralized mechanism, based on voluntarily provided load information by consumers, utilized to determine the price for specific periods [93]. Incentives are also offered to customers in a bid to encourage them to provide correct information. This pricing scheme is also useful in lowering electricity consumption as well as load shifting.

\section{Players and Interactions in GB Flexibility Market}

Developments in the power network have created new roles and relationships for all interacting players within the electricity system [94]. In fact, the modern electricity systems can now be modeled as a networked environment where duplex communication exists between participants. A report published by Origami in 2019 [95] indicated that although a majority of countries are moving towards a DSO flexibility markets using more decentralized and distributed energy usage using DR as a grid security support, they are still in at a trial stage. GB, Australia and North America are the only countries that have a roadmap and plan to turn this to a business as usual solutions.

Since the focus of the trials and innovation pilots categorized and analyzed in this paper are focused on GB network, this section provides useful definitions of the key players in the flexibility market of the future DSO in GB. Figure 5 shows a block diagram illustrating the communication between various players within the GB energy network [96]. As can be seen, the key participants are consumers, electricity suppliers, DSOs, aggregators and data sharing platforms with Office of Gas and Electricity Markets (Ofgem) as the regulatory body. However, the actual model can vary according to network structures of each country.

The role of DSO is to provide a secure network with services including voltage control and network restoration. DSOs do not generate or sell energy as this is the responsibility of energy suppliers. The cost of DSO services, also known as Distribution Use of System (DUoS), is normally added to consumer's bill which is regulated by Ofgem. Usually residential consumers pay a fixed rate of DUoS and the electricity price are limited to certain ToU tariffs. Incentives are offered to DSOs to investigate innovations for efficiency and power quality improvement. As discussed previously, the current GB distribution network is operated by DNOs whose roles are now changing to DSOs. The current GB network is serviced by six different DNOs that are responsible for specific regional areas [97]. Energy Suppliers acquire electricity from either wholesale markets or directly from generators, which is then sold to individual customers. There are currently six main suppliers in GB [98] and their primary focus is to provide 
a competitive tariff to maximize their market share. This has been the driving force behind the move towards dynamic tariffs.

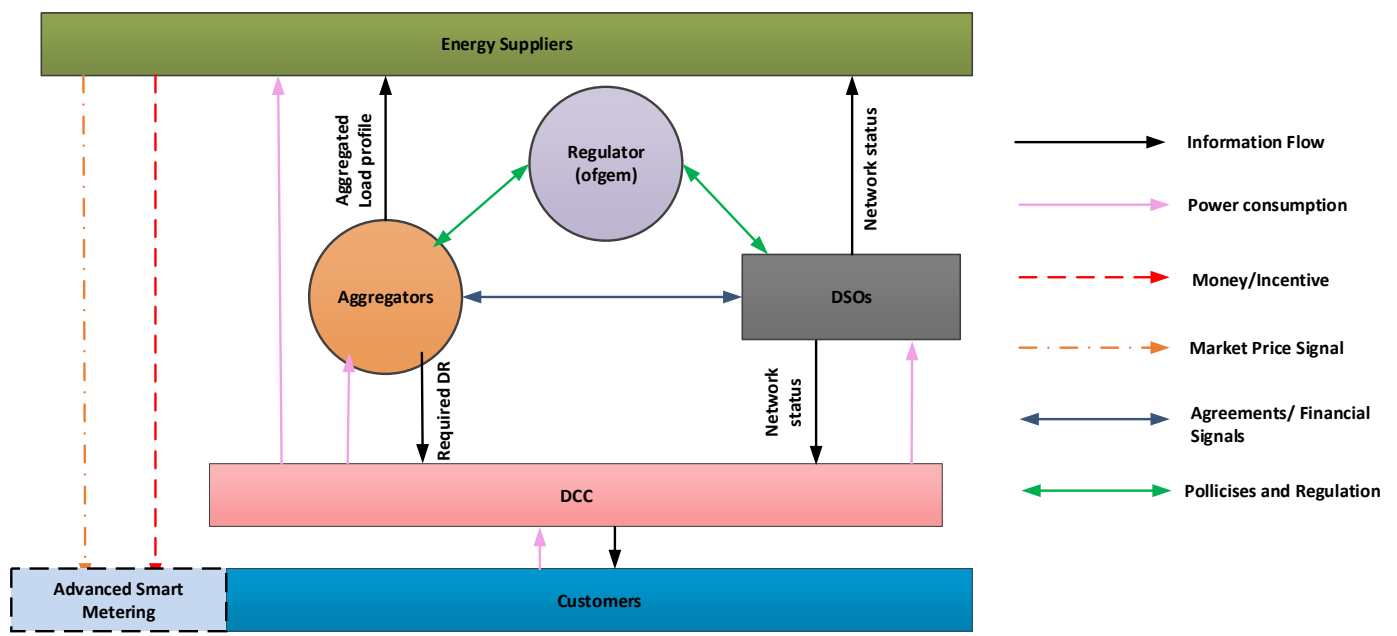

Figure 5. Block diagram of DR participants' interaction in future GB DSO network [96]

Consumers are now able to take an active role in the network and this has created new sources of flexibility. One in four households are now equipped with smart meters that can provide accurate and real time energy consumption data profiles. Besides relaying their demand information, they can also monitor and control their consumption. Ofgem reported a total customer savings of $£ 6.43$ billion in 2010, with $34 \%$ attributed to load shifting/ToU tariffs [99].

The benefits of using smart meter can go far beyond price-based DR. In practice, a successful DR model at lowvoltage level is only feasible if considered in an aggregated level. Aggregators collect the demand flexibility and local generation across their domain regardless of energy supplier or DSO and this increases the network reliability. They act as an interface between energy consumers and other stockholders [100]. This third party entity's role is to enable the active participation of small responsiveness demand in DR programmes. They are also more knowledgeable of market rules compared to individual households and their responsibilities include satisfying all participants' interests.

An Energy management system, comprising energy monitoring, control, and optimization, requires a dynamic data exchange between DSOs, energy suppliers and individual or aggregated end users. For security and privacy reason, home energy consumption data will be available through a centralized and single point thus requiring a data access \& data sharing framework. The Data Communication Company (DCC) [101] is responsible for data communication establishment and management in GB. This network entity acts as an interface between smart meters and other authorized entities in the network. Smart meters can thus preserve their smart functionality regardless of consumer's energy supplier. However, the optimal platform for data exchange interaction between aggregators and DSOs as well the communication standard needs to be defined by DSOs.

It is worth mentioning that a survey by KPMG5 in 2020 [102] reported that the key challenges that the DSOs in Europe are facing is the lack of comprehensive understanding and definition of market rules and regulations. This slows down the development of the required tools and infrastructures of enablers for DSO model implementation 
and the usage of DR. A framework and the role of independent aggregators need to be defined in order to allow their maximum participation s into the energy markets [2].

\section{Demand Response Targets}

The strategies adopted when designing and implementing DR control mechanisms can be based on economic and technical aspects. The literature reviewed has been classified according to these two aspects.

\subsection{Economic Targets}

The economic target of DR control schemes refers to the consideration of electricity cost and incentives in the objective function of Residential Demand Response Aggregators (RDRA). The algorithms and control mechanisms for DR reviewed in this paper are considered from the network point of view, with RDRAs as the studied targets. These aggregators interact with their associated households in order to implement DR services, taking into account their own profit. Their strategy is based on either minimizing cost or maximizing profits/incentives. Several attempts have been made in studying the roles and advantages of RDRA [103-105]. Applying RDRA to provide an active energy management environment has also been considered in a diverse range of studies [106-108].

Based on their objectives, DR aggregators have been grouped into three categories applying various price-based tariffs including ToU, Day-Ahead (DA) and RTP as presented in Table 1. Profit and social welfare maximization focus on single RDRAs serving multiple households. On the other hand, for the electricity market category, several aggregators are considered.

Table 1. Classification of papers based on RDRAs' objectives

\begin{tabular}{c|ccc}
\hline DR Tariff & ToU & DA & RTP \\
\hline Objective & & & \\
\hline Profit Maximization & {$[109,110]$} & {$[111,112,113]$} & {$[109,112,114,115]$} \\
\hline $\begin{array}{c}\text { Social Welfare } \\
\text { Maximization }\end{array}$ & {$[116,117,118,119,120]$} & {$[119,121,122,123,124,125$,} & {$[110,116,117,119,120,123$,} \\
& & $126,127,128]$ & $125,127,129,130,131,132,133]$ \\
\hline Electricity Market & {$[134]$} & {$[122,135,136,137,138,139]$} & {$[139,140,141,142,143]$} \\
\hline
\end{tabular}

In the first category, the aim of each RDRA is to provide and sell the DR services to the SOs. This is done through compensation payment to consumers for the changes in their energy usage.

Generally, the DR objective function can be defined as [96]:

$$
\max \left\{R-\sum_{h \in H} C_{h}\left(P_{h}\right)\right\}
$$

where the proceeds of the RDRA and the consumers' incentives are represented by $R, C_{h}$ is the cost and $P_{h}$ is power consumption of end user per hour.

RDRAs have modeled various dynamic tariffs to improve the market decision-making and pricing scheme designs. For instance, the RDRA's objective function proposed in [110] was to maximize the end-user's surplus 
which was calculated by the differentiation between the total agreement and the actual payment of households. The simulation results indicated an approximate $20 \%$ reduction in consumer bills as well as flatter load profiles over time.

In the second category, each entity at the network, seeks to enhance its own profit. This implies that the goal of energy consumers may not necessarily be in line with the RDRA's one. A unified approach was used in [133] to reduce consumers' electricity cost as well as flattening the average load profile. This study was developed based on the proposed framework on [144] to solve its communication problems and shorten processing time by using a parallel architecture. In a different approach, RTP and ToU were combined to mitigate DN overloading [117].

Similar to profit maximization, in the electricity market category the aim is to maximize the DR availability for sale. However, the role of SOs and the contributions of other aggregators in the network are also considered. In other words, the electricity market is modeled with all network entities having a self-interested and non-cooperative nature. In this model, SOs aim to minimize the cost of network operation by providing rewards to RDRAs.

\subsection{Technical Targets}

The residential responsive demand can contribute in the management of the DN at two levels: local DR, where the focus of the implementation is on the low voltage networks, and wide-area DR management, which analyzes the application of DR at Medium Voltage/Low Voltage (MV/LV) network levels. Table 2 presents an overview of recently published literature in this area. In local DR, the system model comprises one SO that serves a secondary substation which plays the role of an aggregator connected to several domestic loads. However, detail about the DR request and control strategies from the SO is [145] not a requisite and is assumed to be known. At MV/LV network level, the SO interacts with RDRAs in LV feeders to improve the reliability and security of the DN.

Table 2. Technical DR targets classification.

\begin{tabular}{c|cc}
\hline Network Level & Local DR $(\mathbf{L V})$ & Wide-area DR (MV/LV) \\
\hline \multirow{3}{*}{ Ref } & {$[146,147,148,149,150,151,152,153$,} & \\
& $154,155,56,157,158,159,160,161,162$, & {$[153,168,169,170,171$,} \\
& $163,164,165,166,167]$ & $172,173,174,175,176]$ \\
\hline
\end{tabular}

Generally, consumers can contribute towards solving operational issues in the network through DR events. In the case of a DR event, the required demand limit is either allocated to each consumer/feeder or the required load curtailment is automatically applied. The former action refers to EDR programmes where contribution in the DR scheme is voluntary whereas the latter relates to DLC programmes.

The strategies to define the allowable demand for each household/feeder can be categorized into: Curtailment Potential Scheme (CPS), Flexibility Energy Scheme (FES) and a combination of both. A categorized list of research work is shown in Table 3. In CPS, individual available DR is considered for determining the total required curtailment. In FES, the objective function of the feeder controller also takes into account the household's characteristics. Therefore, the DR mechanism seeks to maximize the consumer's comfort while also maintaining the network constraint within limits. However, this increases the complexity of the computational process and necessitates the use of more advanced optimization techniques. 
Table 3. Categorization of methodologies for calculating the allowable demand of households.

\begin{tabular}{c|ccc}
\hline \multirow{2}{*}{ Methodology } & $\begin{array}{c}\text { Curtailment Potential Scheme } \\
\text { (CPS) }\end{array}$ & $\begin{array}{c}\text { Flexibility Energy Scheme } \\
\text { (FES) }\end{array}$ & CPS/FES \\
\hline \multirow{2}{*}{ Ref } & {$[117,147,151,158,159,160$,} & {$[149,152,154,155,156$,} & \\
& $162,163,165,177]$ & $166,167,178,173,174,175]$ & {$[157]$} \\
\hline
\end{tabular}

\section{Demand Response Solution}

The interaction between DR participants in the network has been modelled through several frameworks in the literature. The overall goal of a DR framework is to determine an optimal load scheduling in order to manage the DN. The model consists of households connected to a Load Service Entity (LSE) such as a DSO. Upon receiving a DR event signal from the LSE, households adjust their controllable appliances' operations accordingly to:

- Maximize the social welfare

- Limit the overall household demand within thresholds during peak time

- Meet all household and network constraints

As an example, a residential DR was proposed in [64, 178] as a multi objective function to minimize power losses in the network while maximizing the use of flexible demand. It was concluded that the voltage sensitivity to changes in demand is greater at the buses located at the end of the feeder. It was also shown that the selection of setting parameters for DR objective is important to avoid rebound peaks.

A DR framework and structure should be able to provide an integrating environment for all entities, with specific attributes, in the network. Therefore DR can maintain network constraints within the boundary limits while meeting all DR participants' goals. Three framework models from the literature are discussed further.

A multi-layer framework comprises several layers where entities within the same layer have similar attributes or functionalities [179, 181]. For example, a two-layer framework proposed in [139], as shown in Figure 6, has all direct participants in electricity market in the first layer. The entities in the second layer, on the other hand, are consumers providing DR services.

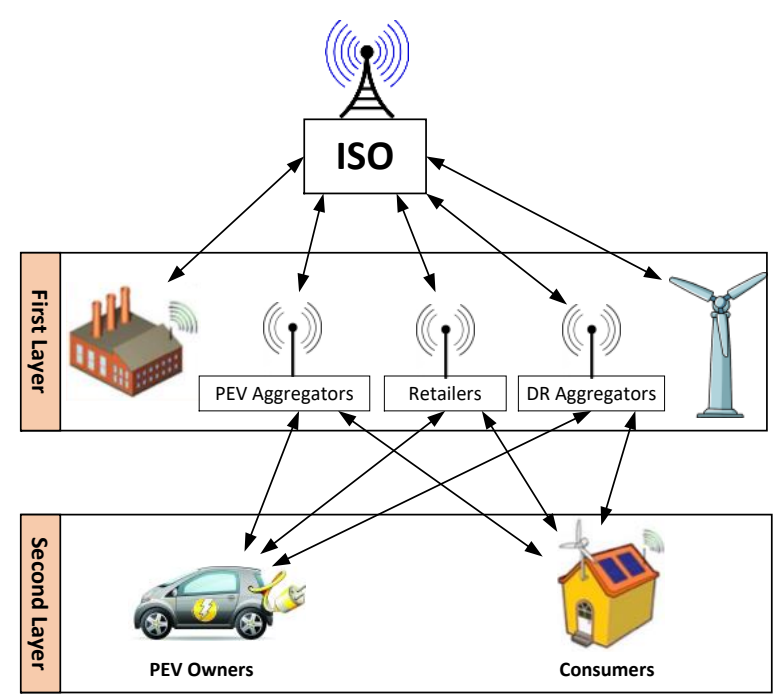

Figure 6. Multi-layer framework [139] 
A Hierarchical Framework comprises entities in different levels where they are able to communicate with entities on their upper level. Typically DR controllers, e.g., LSE and DSO, are located at the top level whereas end users are in the lower levels. This structure is also known as supervisor-employee model. In the three-level structure [134] shown in Figure 7, aggregators are defined in the second level, acting as an interface between the first and third level.

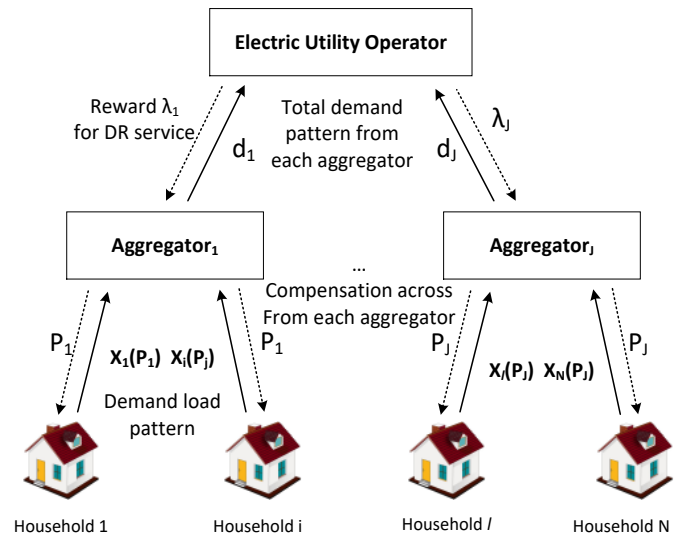

Figure 7. Hierarchical framework [134]

A Multi-Agent-System (MAS) framework models network entities as agents with specific characteristics, functionalities and behaviors [157]. Although autonomous, they interact with each other to reach the overall system goals by splitting and sharing the tasks. In [182] four types of agents, as depicted in Figure 8, are introduced to represent generators, wholesale markets, retailers and households.

The main difference between the Hierarchical and Multi-layer frameworks is that in the former, each entity can only interact with another one in its upper level while in the latter there is no restriction in communications between layers.

The complex nature of the future electricity network makes MAS the most suitable model due to its decentralized structure where each intelligent agent can act independently and simultaneously [170]. This can also maximize the network stability in the occurrence of local fault or communication failure [94]. A comprehensive literature on DR implementation studies using MAS have been presented in [183]. A review of the applications of MAS in managing smart grids [184] showed the benefits of this decentralized approach in reducing cost, enhancing customer welfare and in providing a framework to maximize integration of low carbon technologies. However,

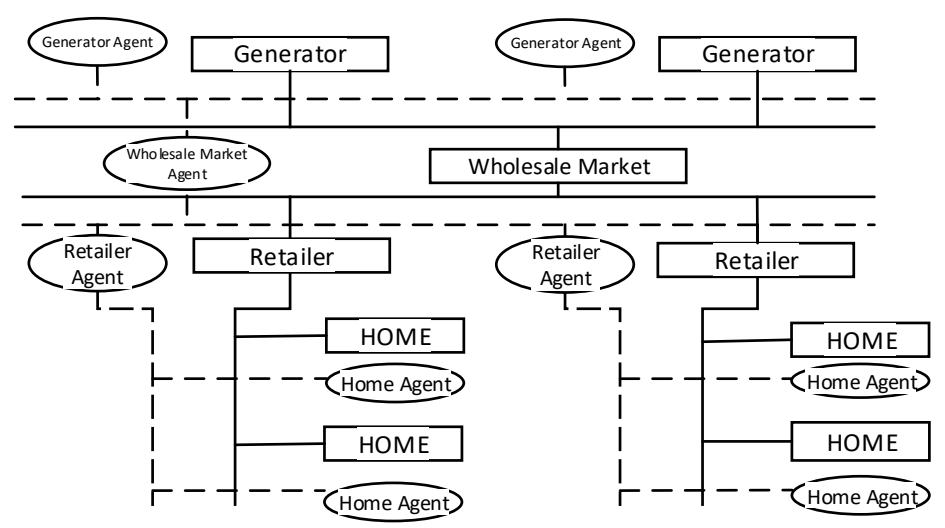

Figure 8. MAS framework [182] 
the proposed MAS frameworks in the literature are limited in terms of scalability [139, 134], adoptability [185] , the number of manageable network constraints $[153,168,186]$, DR scenarios $[14,35,38]$ and types of agents $[187$, $188]$.

\section{Demand Response Application for Distribution Network Management}

The DNs mainly deal with three major operational issues: transformer overloading, voltage limits and network congestion. Generally, network congestion occurs at MV networks while transformer overloading is mostly at LV networks. A classification of these categories from the literature is provided in Table 4.

\subsection{Transformer Overloading Management}

Exceeding the maximum capacity of a MV substation or MV/LV transformer can be the cause of overloading issues at LV feeders. During such conditions, the duration of the DR event and the extent of load shedding are two parameters considered for maintaining the demand within acceptable limits.

Many approaches have been devised and studied with the aim of overcoming the overloading challenges in DNs. One such DR control strategy involved the integration of local generation to relieve congestion [151]. Another study [152] applied a direct load control approach based on a merit order and confirmed the achievability of a $100 \%$ PV penetration in the LV network. Similarly, [154] proposed an EDR mechanism aimed at lowering the transformer power demand. However, in these studies the demand allocation is assigned to consumers without considering their individual characteristics. These can increase the possibility of a power rebound. [155-156] addressed this issue using a MAS framework where households' atributes, including user constraints, satisfaction level and appliances, are also taken into account during a DR event. Hence, the drawbacks of having a new peak load after DR event duration can be lessened.

Table 4. Classification of DR application

\begin{tabular}{c|c}
\hline Constraint & \multicolumn{1}{c}{ Reference } \\
\hline Voltage & {$[145,147,150,155,158,159,163,165,166,167,173,174,175,189,190]$} \\
Transformer Overloading & {$[151,152,154,156,160]$} \\
Congestion & {$[145,147,150,155,158,159,163,165,166,167,173,174,175,189,190]$} \\
Combination & {$[146,149,157,168,191]$} \\
\hline
\end{tabular}

\subsection{Congestion Management}

Price-based DR is the main mechanism proposed in the literature to manage the congestion at the DN. The methodology is split into four steps:

- DR Aggregators update their load profiles based on individual demand from their corresponding households.

- An initial demand bid is sent to the DSO in a day ahead or real time market.

- The DSO adds a supplementary cost to the existing tariff in case of any possible congestion.

- Accordingly, aggregators adjust their demands based on the updated price. 
Several methods have been presented in order to determine the congestion price. In [153] a Locational Marginal Pricing (LMP) is applied and showed peak overloading of $1 \%$ and $2 \%$ during night and morning respectively. [169] used a dynamic thermal model of the transformer which also verified the effectiveness of such a price-adjustment programme as an economic tool to reduce peak demands.

In a different real-time pricing DR [172], the pricing tariffs and additional overloading costs are allocated distinctively to each zone (feeder) of the network. This can provide a more localized and distributed control of the network. However, the proposed pricing scheme faces many challenges. For instance, since the consumers have to pay the price of local problem at the network, their attitudes toward DR participation can decrease.

Consumers in RTP can decide about their consumption behavior at any given time. Therefore, a direct DR control mechanism is usually necessary along with price-based DR in order to guarantee the provision of adequate flexible demand. A combination of both DR types can ensure the generation-demand balancing in the DN [169]. An approach in [171] integrates both incentive and price-based DR schemes, based on the available DR size under normal conditions and during emergency conditions respectively.

\subsection{Voltage control}

The uncertainity in renewable energy generation and increase in demand can cause the voltage to exceed its allowable limits. Voltage violations, under-voltage and overvoltage, can occur at both LV and MV feeders. This can lead to voltage drops and consequently power cut. The literature mainly considered the incentive-based DR such as DLC or EDR where consumers in pre-agreed contracts can be involved in load reduction schemes if required.

At the LV network, this problem, in the case of solar energy, has been mainly addressed by controlling the active power through PV invertors. In order to alleviate the voltage constraint in the network, several methods of droop control, such as Active Power-Voltage (P-V) [157-159], Reactive Power-Voltage (Q-V) [148, 177] and Active Power-Frequency (P-f) [160], have been proposed and applied. The maximum output set point is determined for the PV invertor where it is decreased during voltage drop issues.

A distributed DR mechanism is applied in other studies to control the power usage of home appliances. In [155] the amount of load curtailment for each household is determined and allocated according to the size of their electrical panel. However, voltage problems at LV feeders are primarily studied in the form of a combined approach together with congestion management.

At MV feeders, to improve the voltage stability of the network, the identification of the buses characteristics regarding their voltage sensitivity is required. Many studies [150,174, 189, 192] have shown that DR can be used as an effective tool to reduce the overall voltage drop across the network and to increase it at the end of the feeders. The main concerns in designing and applying DR mechanisms are the determination of the quantity and optimal load curtailment at each feeder. The former is mostly calculated using optimisation techniques which aim at determining the minimum required DR size [173] or maximum load capacity of each bus [174]. The latter is usually determined by voltage sensitivity analysis using several methods such as:

- $\quad$ Voltage Deviation Index (VDI) [193-196]

- Updated version of Jacobian matrix [197-198]

- Direct approach dependent on the network topology [199-200] 
- $\quad$ Adjoint network model [201]

- Y-matrix model [202-203]

- Constant current model [204-205]

- Bus power flow model [175, 202-203]

After calculating the voltage senstivity of all buses in the network, two methodologies are utilized in the literature for shedding the required demand reduction:

Loop procedure $[189,192]$ is one in which the load shedding procedure initially begins at the buses with the biggest magnitude of voltage deviation. The process terminates when the voltage is back within the statutory limit. This method is applicable especially when the required amount of DR is not identified.

Distributed Curtailment $[150,208]$ is another methodology in which the total required load curtailment is distributed among buses based on their voltage sensitivity. This technique is mainly suitable where the total required DR size is known.

One important issue to consider in DR implementation is addressing Demand Response Mismatch (DRM) [209], which are inconsistencies between scheduled and actual DR. Inclusion of reactive power and voltage dependency in DR calculations can help to mitigate this problem and improve reliability of power systems [210-211].

\subsection{Unified Approach}

Due to the correlative nature of constraints at the DN, several studies have examined unified-based approaches where more than one constraint are considered. A hierarchical agent-based model is proposed in [157] that analyzed both voltage and thermal limits. The PV output and heat pump are controlled using CPS-DLC and FES methodologies respectively. In [149] a two-level hierarchical DR framework consisting of two DR controllers is presented: one for improving the voltage profile and the other for controlling the transformer overloading. The first target is achieved through incentives allocated to consumers for shifting their loads. In the latter, this is done through peak load shaving. A new approach is presented in [146] to mitigate the voltage and current constraints within the limits. Unlike other studies, where the DR objective function is to minimize the power losses and/or voltage deviation index, here the maximization of the allowable total demand is considered.

\section{DR Strategies in Microgrid}

The need for implementing microgrids has been accentuated by the challenges to efficiently manage the integration of distributed energy resources (DER) with the view to decentralize, decarbonize and improve grid reliability and resilience at lower cost [212]. Microgrids have two operating capabilities: autonomous and on-grid. In on-grid mode, local power generation is the first choice for meeting demand of the microgrid, and any excess power required or generated are either imported from or supplied to the grid. In autonomous mode, it is vital for generation to match demand for stability of the microgrid [213]. Several approaches have been investigated to maintain this balance. One of the most efficient and reliable methods is through DR [214-215]. [216] proposed a flexible microgrid where boundaries can be adjusted based on factors such as DR levels and customer comfort amongst others. This method resulted in utilities cost reduction of up to $19 \%$ compared to static microgrid operation.

DR control mechanisms are either performed offline, e.g., incentive-based [214, 216] and day-ahead [215] , or, online, such as RTP [213]. Studies have shown that the latter is more reliable, efficient and practical when dealing 
with uncertainties in the microgrid [217]. However there are still serious concerns about the resilience, efficiency and stability of microgrids due to the dynamic nature of DERs [218-223]. Most research works have only studied microgrids under normal conditions or with minor faults [220-231]. Recent studies have proposed, developed and implemented various multi-objective optimization (MOO) methods to improve the reliability of microgrids under major network faults, system failures and load unbalance [232]. In this paper a new decentralized control strategy for microgrids in both offline and real-time environments have been performed using a combination of MOO and fuzzy decision making to improve the fault ride through capability. The disturbance in that microgrid has been modelled as non-linear constraints for MOO to guarantee the optimum power sharing. H.R. Baghahee et al. [233], have used multi objective particle swarm optimization to overcome the computational burden for optimum coordination of overcurrent relays in meshed and interconnected networks. It is to be noted that the application of $\mathrm{MOO}$ is not limited to the improvement of stability and resilience only. It can also be used in designing and optimizing hybrid energy systems [234-238], in cost minimization of the system over long operation periods [239], as well as in optimization of transmission system devices [240].

Detailed studies in the use of intelligent algorithms, such as evolution and metaheuristic, as solutions to multiobjective optimization have been performed in areas such as microgrids and renewable energy generations [153,187190]. Results demonstrated the effectiveness of such techniques in achieving global optima. In [218, 241] a novel load flow methodology has been presented for radial and meshed networks, which can solve nonlinearities in the load flow. Using this method, [242] introduced a hierarchical 3-level control strategy to calculate the reactive set points of DR controllers in any type of microgrid. This control scheme can enhance the stability and ameliorate power sharing using more accurate power calculations. A similar approach [241, 243] was adopted to include nonlinear and sensitive loads.

Moreover, optimal sizing and optimal power management strategies are also integrated with modern DR schemes. In this kind of solution, the initial set points of the control system are determined by a robust power flow algorithm that can efficiently solve the load flow problem in the microgrid with high values and uncertainties in R/X ratio and load multiplier.

However, adopting an optimized and coordinated energy management system such as a multi-microgrid approach can be more efficient and cost effective. This strategy discourages individual microgrids from misusing common resources and instead acts towards the best interests of the whole system [215] .

\section{Overview of GB Demand Response Innovation Pilots}

Innovation pilots are projects that apply novel solutions as replacements for expensive upgrades of the network with a view to providing economic benefits to both consumers and the DNO [244]. This section briefly reviews the activities in terms of residential DR related pilot projects that have been trialed in GB. They are classified using the following categories: global demand response, active network management and community engagement.

\subsection{Global Demand Response}

The trials in this category have the aim of introducing various DR pricing schemes to financially encourage consumers to lower or shift their peak power consumption. ToU and dToU have been the only implemented tariffs so far in GB and their efficacy has been investigated through different pilots [245] as summarized in Table 5. 
Table 5. Summary of relevant innovation pilots in GB network with the focus on global DR.

\begin{tabular}{|c|c|c|c|c|c|}
\hline Category & & \multicolumn{3}{|c|}{ ToU } & dToU \\
\hline Trial & $\begin{array}{l}\text { Customer Lead } \\
\text { Network } \\
\text { Revolution }\end{array}$ & $\begin{array}{l}\text { Ireland Electricity } \\
\text { Smart Metering } \\
\text { Behaviour Trials }\end{array}$ & $\begin{array}{l}\text { Energy Demand } \\
\text { Research Project }\end{array}$ & $\begin{array}{l}\text { Northern Ireland } \\
\text { Powershift }\end{array}$ & $\begin{array}{l}\text { Low Carbon } \\
\text { London }\end{array}$ \\
\hline Organisation & $\begin{array}{l}\text { Northern } \\
\text { Powergrid }\end{array}$ & $\begin{array}{l}\text { Commission for } \\
\text { Energy Regulation } \\
\text { within the Republic } \\
\text { of Ireland }\end{array}$ & $\begin{array}{l}\text { EDF, E.ON, Scottish } \\
\text { Power and SSE }\end{array}$ & $\begin{array}{l}\text { Northern Ireland } \\
\text { Electricity. }\end{array}$ & $\begin{array}{l}\text { EDF, UK Power } \\
\text { Networks }\end{array}$ \\
\hline Location & $\begin{array}{l}\text { North of } \\
\text { England }\end{array}$ & Ireland & $\begin{array}{l}\text { London and the } \\
\text { southeast of England }\end{array}$ & Northern Ireland & London \\
\hline Time Period & $2010-2015$ & $2009-2010$ & $2007-2010$ & 2003- 2004 & $2010-2014$ \\
\hline Innovation & $\begin{array}{l}\text { Assess the } \\
\text { impact of low } \\
\text { carbon } \\
\text { technologies } \\
\text { including PVs, } \\
\text { HPs and EVs } \\
\text { and ToU for } \\
\text { residential, } \\
\text { industrial and } \\
\text { commercial } \\
\text { customers }\end{array}$ & $\begin{array}{l}\text { Investigate the } \\
\text { potential of smart } \\
\text { meters, ToU tariffs } \\
\text { and Demand Side } \\
\text { Management } \\
\text { (DSM) stimuli on } \\
\text { load } \\
\text { reduction/shifting }\end{array}$ & $\begin{array}{l}\text {-Trials by four energy } \\
\text { suppliers } \\
\text {-Investigate the effect } \\
\text { of supplying } \\
\text { information on long } \\
\text { term consumption }\end{array}$ & $\begin{array}{l}\text { Evaluating the } \\
\text { potential of shifting } \\
\text { peak demand } \\
\text { through ToU tariff }\end{array}$ & $\begin{array}{l}\text { Investigating the } \\
\text { impact of dToU on } \\
\text { demand-supply } \\
\text { balancing and } \\
\text { network constraint } \\
\text { management }\end{array}$ \\
\hline Scale & $\begin{array}{l}11,000 \text { homes } \\
(2000 \text { others })\end{array}$ & 5,028 homes & 60,000 homes & 200 homes & 5,533 homes \\
\hline $\begin{array}{c}\text { Solutions and } \\
\text { Technologies }\end{array}$ & $\begin{array}{l}\text { ToU, Smart } \\
\text { meters }\end{array}$ & $\begin{array}{l}5 \text { ToU rates, bi- } \\
\text { monthly billing } \\
\text { with a demand } \\
\text { reduction incentive }\end{array}$ & $\begin{array}{l}\text { Financial incentives for } \\
\text { consumption below } \\
\text { target Smart meters }\end{array}$ & $\begin{array}{l}\cdot 3 \text { ToU rates } \\
\text {-Keypad meter with } \\
\text { an IHD }\end{array}$ & dToU \\
\hline $\begin{array}{l}\text { Communication } \\
\text { Strategies }\end{array}$ & Home display & $\begin{array}{l}\text { bi-monthly billing, } \\
\text { monthly billing, bi- } \\
\text { monthly billing } \\
\text { with an electronic } \\
\text { energy monitor }\end{array}$ & $\begin{array}{l}\cdot \text { Real time display, } \\
\text {-Letters, } \\
\text { •Website }\end{array}$ & & Text messaging \\
\hline Investment & $£ 31$ million & - & $£ 9.75$ million & - & $£ 28$ million \\
\hline $\begin{array}{l}\text { Key Lessons } \\
\text { Learned }\end{array}$ & $\begin{array}{l}\text { Reduce } \\
\text { residential peak } \\
\text { demand by } \\
6.39 \% \text { between } \\
4 \mathrm{pm}-8 \mathrm{pm}\end{array}$ & $\begin{array}{l}\text { Households on } \\
\text { average saved } \\
2.5 \% \text { on bills }\end{array}$ & $\begin{array}{l}\text { Results showed that } \\
\text { overall there was no } \\
\text { significant reduction in } \\
\text { consumption }\end{array}$ & $\begin{array}{l}\text { Annual bills } \\
\text { decreased by } 5.5 \%\end{array}$ & $\begin{array}{l}8 \% \text { reduction in } \\
\text { demand }\end{array}$ \\
\hline
\end{tabular}

\subsubsection{Time-of-Use Tariffs}

The main finding of these trials verified that ToU tariffs can trigger a shift in the demand of households from peak to non-peak period, although there exists a high variation in the outcomes of the trials. It was also found that the effect on peak demand was more significant than that of overall energy consumption. Some projects adopted various ToU tariffs for better comparison. The Energy Demand Research Project (EDRP) [246-247], for instance, used two ToU tariffs from energy suppliers Électricité de France (EDF) and Scottish and Southern Energy (SSE). While EDF's tariff was daily-based, SSE's incorporated seasonal price as well. Peak demand reductions of $8 \%$ and $4 \%$ were observed for weekends and weekdays respectively for a total of 1936 participants [245]. The Ireland Electricity Smart 
Metering Trials (IESMT) [248] adopted five different ToU tariffs and showed 2.5\% - 9\% demand reduction from approximately 5000 households [245]. Another pilot, the Customer Lead Network Revolution (CLNR) [249], resulted in a reduction of $6 \%$ in peak consumption for 600 households [250]. A decrease of $75 \mathrm{~W}$ in peak load per household was obtained through the Energy Control for Household Optimization (ECHO) [251] pilot, which was developed to control shiftable appliances. The Sunshine Tariff [252] yielded a daily 13\% demand reduction for consumers equipped with automated control technology. The outcome of these pilots also concluded that together with economic incentives, education is also a requisite for the successful introduction of ToU. Currently, the emphasis of implementing ToU tariffs is focused principally on awareness and energy engagement.

\subsubsection{Dynamic Time-of-Use Tariffs}

The Low Carbon London (LCL) [253] pilot was the first dToU scheme implemented in the UK. It was aimed to explore the DR potential in various trials run by suppliers or DNOs. The outcomes indicated an increase of up to $14 \%$ in consumption during low price periods and a reduction of $9 \%$ during high price ones. This resulted in bill reduction for $85 \%$ of households with a mean saving of $4.9 \%$.

\subsection{Active Network Management}

ADNM with residential DR services was implemented by some trials. A summary of three major trials aiming to investigate the efficiency of DR in ADNM platforms for managing network constraints and increasing DERs' penetration is provided in this section and in Table 6 .

Table 6. Summary of relevant innovation pilots in GB network with the focus on ADNM.

\begin{tabular}{|c|c|c|c|}
\hline Trial & Shetland Trial & $\begin{array}{c}\text { Customer Load Active System } \\
\text { Services }\end{array}$ & Accelerating Renewable Connections (ARC) \\
\hline Organisation & $\begin{array}{l}\text { Scottish and Southern } \\
\text { Electricity }\end{array}$ & Electricity North West & SP Energy Network \\
\hline Location & Shetland islands & Clusters across GB & Scottish borders and East Lothian area \\
\hline Time Period & 2013-2017 & 2014-2016 & 2012-2014 \\
\hline Innovation & $\begin{array}{l}\text { Evaluating the effectiveness } \\
\text { of DSM on active network } \\
\text { management }\end{array}$ & $\begin{array}{l}\text { Evaluating the application of } \\
\text { innovative voltage, } \\
\text { management technologies to } \\
\text { provide DR services }\end{array}$ & $\begin{array}{l}\text { Combination of ADNM scheme and } \\
\text { community engagement to manage the } \\
\text { generation-supply by generators and locally- } \\
\text { produced energy }\end{array}$ \\
\hline Scale & 234 homes & $\begin{array}{l}60 \text { primary substations serving } \\
\text { approximately } 485,000, \\
\text { Domestic and industrial and } \\
\text { commercial customers }\end{array}$ & Covers geographical area of $2700 \mathrm{~km}^{2}$ \\
\hline $\begin{array}{l}\text { Solutions and } \\
\text { Technologies }\end{array}$ & $\begin{array}{l}\text { Battery and DSM enabled } \\
\text { appliances, ADNM }\end{array}$ & $\begin{array}{l}\text { Cash incentives } \\
\text { Smart voltage control, } \\
\text { advanced active network } \\
\text { management system }\end{array}$ & $\begin{array}{l}\mathrm{PV} \text {, wind turbines, modification of network } \\
\text { equipment, } \\
\text { Incentive on connections engagements }\end{array}$ \\
\hline $\begin{array}{l}\text { Communication } \\
\text { Strategies }\end{array}$ & $\begin{array}{l}\text { Website, phone, home visit, } \\
\text { local meeting }\end{array}$ & Leaflet, website & Workshop with local community, online tools, \\
\hline Investment & $£ 21$ million & $£ 8,084$ million & $£ 8.46$ million \\
\hline
\end{tabular}




\begin{tabular}{|c|c|c|c|}
\hline Trial & Shetland Trial & $\begin{array}{c}\text { Customer Load Active System } \\
\text { Services }\end{array}$ & Accelerating Renewable Connections (ARC) \\
\hline $\begin{array}{c}\text { Key Lessons } \\
\text { Learned }\end{array}$ & $\begin{array}{l}\text { DSM with ADNM platform } \\
\text { can be an alternative for } \\
\text { future DN, } \\
\text { Learning and improving the } \\
\text { relationship with customers } \\
\text { in order to change their } \\
\text { consumption behaviour }\end{array}$ & $\begin{array}{l}\text { ADNM with DR can } \\
\text { successfully provide voltage } \\
\text { and frequency support without } \\
\text { affecting power quality of } \\
\text { network devices }\end{array}$ & $\begin{array}{l}\text { Reduced infrastructure, Lower cost over } \\
\text { traditional solution } \\
\text { Save energy cost for local communities }\end{array}$ \\
\hline
\end{tabular}

The Customer Load Active System Services (CLASS) [254] project was a successful pilot that provided a good insight on the voltage/demand relationship for all participants. The use of smart voltage controllers in major substations demonstrated the application of innovative voltage management approaches to provide DR. Results showed that DR potential of up to $3.3 \mathrm{GW}$ was achieved.

The Shetland Trial [255] provided DR services to 234 participants by replacing their old storage and water heaters with modern smart storage heaters, which were selected for their demand shifting potential. The ADNM computes next day schedules based on requirements obtained daily from devices, before updating them with instructions. The potential for a flexible framework for future changes to the network was clearly demonstrated by this pilot. The Accelerating Renewable Connections (ARC) [256] trialed a combination of ADNM and local community engagement schemes to manage locally generated sources and supply through community engagement. Connections of 49.5MW from wind farms and 2.2MW from PV panels were successfully deployed to local households. Through this project, consumers could potentially save around $£ 1.9$ million over the lifetime of the systems. More recently Smart Energy Isles pilot [257] aimed to increase penetration of renewable energies in a microgrid by improving the existing ADNM. This on-going trial allows local communities to benefit from the maximized local generation.

\subsection{Community Engagement}

These trials were designed to investigate the potential of local communities to engage in DR programmes. The aim was for DNOs to collaborate with consumers to lower demand and maximize the local available DR with a view to deferring network reinforcement investment. Several pilots [239] were implemented to change the customers' behaviors, and avoid peak demands by shifting consumption to non-peak periods. An overview of recent communityrelated pilot projects, categorized according to their focus, is provided in the following sub-section and summarized in Table 7.

\subsubsection{Integrating Low-Carbon Technologies}

This category aims at assessing the efficiency of incorporating renewable energy resources into the DN. The Sola Bristol project [258] for example, equipped participating households with PV panels, energy storage units and operated under ToU pricing. Although the results confirmed the benefits of integrating storage and ToU tariffs, the project could only be economically viable with higher integration of DERs. It was found that a significant effect on DR would be possible with PV installed in no less than $60 \%$ of households. Customer awareness of these energy schemes is instrumental in improving engagement. My Electric Avenue [259] was another such trial and it investigated the effect of charging clusters of EVs on the networks during peak periods. The results from analyzing various LV networks across Britain indicated that with an $\mathrm{EV}$ penetration of $40 \%-70 \%, 32 \%$ of $\mathrm{LV}$ feeders would necessitate intervention. A recently started trial, Multi Asset Demand Execution (MADE), is assessing the potential 
flexible DR from multiple energy assets including EVs, HPs and PVs under fixed and dToU tariffs. Conflicts of interest in the provided DR methodology between local community and network operator, technical and environmental impact on the whole network and possible energy consumers' saving are the expected key learnings.

\subsubsection{Customer Awareness}

In this category, the objective of trials is to raise awareness and to educate customers about the energy schemes. Consumers are kept up-to-date with the development of the trial and their benefits in order to encourage them and maintain their interests in the schemes. The Energywise [260] project was developed to focus on fuel poor consumers to provide them with the prospect of taking part in DR opportunities. The motivations for customers to engage with this project included energy cost reduction, better knowledge of energy consumption and provision of complementary energy devices. The Solent Achieving Value from Efficiency (SAVE) [261], was another such project, which aimed at evaluating the viability of energy efficiency schemes and engagement in order to alleviate network constraints. This trial involved the use of energy coaches working at local community level to improve awareness of responsible energy usage and sustainability. People were encouraged towards sustained behavior change through the use of drivers such as community engagement events.

\subsubsection{Incentives}

These pilots aimed at maximizing customer engagement by providing attractive incentives. The Activating Community Engagement (ACE) [262] trial developed and run an online game where customers earned credits for reducing their consumption during specific periods. Prizes were awarded to winning communities as well as individual participants. In a different community engagement trial, the Power Savers Challenge [263], customers whose demands were less than the previous year were rewarded. 251 households took part in this trial and a total demand reduction of 201MW was achieved. $70 \%$ of participating communities reached their targets, achieving a reduction of $4 \%$ as compared to 2013. Another such pilot, Energy Action [264], implemented a reward scheme for 10 communities to maintain their consumption under the transformer maximum capacity. The study concluded that financial community incentives were not enough to guarantee a high level of response due to the unpredictability of community demands.

\section{Discussion of Key Challenges and Future Directions}

The DR researches and trials reviewed in this paper show that utilization of flexibility provided from residential loads or local generations can be beneficial for DSOs and end-users in several means. An incremental interest in innovation projects trialed in GB proves the potential of this solution in managing the networks' constraints. However, in reality, the wider DR implementation for residential energy users faces several challenges and limitations. This has restrained the projects' scopes and scales and concealed the actual value hidden in the back of these available energy resources. This section classifies the key challenges according to technical, social and financial perspectives and provide some recommendations as a future direction for researchers in this field and industry practitioners. 
Table 7. Summary of relevant innovation pilots in GB network with the focus on community engagement

\begin{tabular}{|c|c|c|c|c|c|c|c|c|c|c|}
\hline Category & Trial & Organisation & Location & $\begin{array}{c}\text { Time } \\
\text { Period }\end{array}$ & Innovation & Scale & $\begin{array}{l}\text { Solutions and } \\
\text { Technologies }\end{array}$ & $\begin{array}{l}\text { Communication } \\
\text { Strategies }\end{array}$ & Investment & Key Lessons Learned \\
\hline \multirow{2}{*}{ 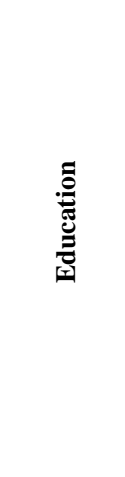 } & $\begin{array}{l}\text { Solent } \\
\text { Achieving } \\
\text { Value from } \\
\text { Efficiency }\end{array}$ & $\begin{array}{l}\text { Scottish and } \\
\text { Southern } \\
\text { Electricity }\end{array}$ & Solent & $\begin{array}{l}2014- \\
2019\end{array}$ & $\begin{array}{l}\text { Testing cost } \\
\text { effectiveness of } \\
\text { energy efficiency } \\
\text { measurements } \\
\text { and engagement }\end{array}$ & $\begin{array}{l}4,600 \\
\text { homes }\end{array}$ & $\begin{array}{l}\text {-Financial incentive, } \\
\text {-Community energy } \\
\text { coaches } \\
\text {-Deploying LED lighting }\end{array}$ & $\begin{array}{l}\text {-Personalized data-driven } \\
\text { messaging, } \\
\text { • One-by-one written } \\
\text { contact, } \\
\text {-Community engagement }\end{array}$ & $£ 7$ million & $\begin{array}{l}\text { Consumers engaged better } \\
\text { with local community than } \\
\text { DNOs }\end{array}$ \\
\hline & Energywise & $\begin{array}{l}\text { UK Power } \\
\text { Networks }\end{array}$ & $\begin{array}{l}\text { Tower } \\
\text { Hamlets, } \\
\text { East } \\
\text { London }\end{array}$ & $\begin{array}{l}2014- \\
2017\end{array}$ & $\begin{array}{l}\text { Testing the } \\
\text { effects of demand } \\
\text { reduction } \\
\text { techniques for } \\
\text { fuel poor } \\
\text { customers }\end{array}$ & $\begin{array}{l}538 \\
\text { homes }\end{array}$ & $\begin{array}{l}\text { - ToU, incentives } \\
\text { (vouchers, etc.) } \\
\text {-Smart meters, smart } \\
\text { energy monitor and } \\
\text { devices, } \\
\text {-Temperature monitoring } \\
\text { equipment }\end{array}$ & $\begin{array}{l}\text {-Face-to-face } \\
\text { communication, } \\
\text {-Dedicated support line, } \\
\text { - Community engagement, } \\
\text {-Engagement strategy and } \\
\text { materials }\end{array}$ & $£ 5.49$ million & $\begin{array}{l}\text { Successful engagement due } \\
\text { to tailored approach }\end{array}$ \\
\hline \multirow{3}{*}{ 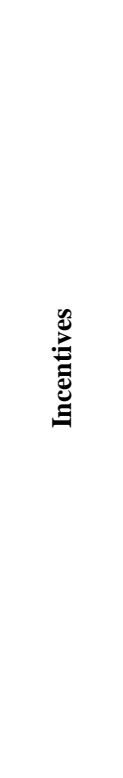 } & $\begin{array}{l}\text { Activating } \\
\text { Community } \\
\text { Engagement }\end{array}$ & $\begin{array}{l}\text { Northern } \\
\text { Powergrid }\end{array}$ & $\begin{array}{l}\text { County } \\
\text { Durham }\end{array}$ & $\begin{array}{l}2015- \\
2017\end{array}$ & $\begin{array}{l}\text { Community } \\
\text { engagement } \\
\text { through online } \\
\text { gaming to } \\
\text { achieve demand } \\
\text { reduction }\end{array}$ & - & $\begin{array}{l}\text {-Incentives based on } \\
\text { demand reduction, } \\
\text {-Smart plugs }\end{array}$ & $\begin{array}{l}\text {-Online game, } \\
\text {-Posters and flyers, } \\
\text { •Educational programme, } \\
\text {-Council website, } \\
\text {-Community engagement }\end{array}$ & $£ 1.1$ million & $\begin{array}{l}\text { - Complete understanding at a } \\
\text { participant level is crucial } \\
\text {-Importance of providing } \\
\text { adequate and not } \\
\text { overwhelming information to } \\
\text { participants }\end{array}$ \\
\hline & $\begin{array}{l}\text { Power } \\
\text { Savers } \\
\text { Challenge }\end{array}$ & $\begin{array}{l}\text { Electricity } \\
\text { North West }\end{array}$ & Stockport & $\begin{array}{l}2013- \\
2015\end{array}$ & $\begin{array}{l}\text { Increasing } \\
\text { capacity for } \\
\text { renewable energy } \\
\text { generation on the } \\
\text { DN }\end{array}$ & $\begin{array}{l}251 \\
\text { homes }\end{array}$ & $\begin{array}{l}\text {-Incentives based on the } \\
\text { consumption of previous } \\
\text { year } \\
\text {-LED light bulbs, shower } \\
\text { timers, Plug-in timers }\end{array}$ & $\begin{array}{l}\text {-Newsletter, online, } \\
\cdot \text { Events and advice, } \\
\text {-Home display, } \\
\text {-Community engagement }\end{array}$ & - & $\begin{array}{l}\text {-Participants well supported } \\
\text { and engaged } \\
\text {-Importance of providing } \\
\text { adequate and not } \\
\text { overwhelming information to } \\
\text { participants }\end{array}$ \\
\hline & $\begin{array}{l}\text { Community } \\
\text { Energy } \\
\text { Action }\end{array}$ & $\begin{array}{l}\text { Western } \\
\text { Power } \\
\text { Distribution }\end{array}$ & $\begin{array}{l}10 \\
\text { locations } \\
\text { from } \\
\text { central to } \\
\text { south } \\
\text { west } \\
\text { England }\end{array}$ & $\begin{array}{l}2012- \\
2013\end{array}$ & $\begin{array}{l}\text { Assessing the } \\
\text { feasibility of } \\
\text { reducing peak } \\
\text { demand by DSM } \\
\text { in predictable and } \\
\text { reliable }\end{array}$ & $\begin{array}{l}834 \\
\text { homes }\end{array}$ & $\begin{array}{l}\text { Cash incentives for each } \\
\text { peak and overall } \\
\text { consumption reductions } \\
\text { targets for each community }\end{array}$ & $\begin{array}{l}\text { - Newsletter, online, } \\
\text {-Leaflet, } \\
\text {-Door knocking }\end{array}$ & - & $\begin{array}{l}\text { Methodology was not } \\
\text { successful and not } \\
\text { recommended as a way to } \\
\text { reduce demand }\end{array}$ \\
\hline
\end{tabular}




\begin{tabular}{|c|c|c|c|c|c|c|c|c|c|c|}
\hline Category & Trial & Organisation & Location & $\begin{array}{l}\text { Time } \\
\text { Period }\end{array}$ & Innovation & Scale & $\begin{array}{c}\text { Solutions and } \\
\text { Technologies }\end{array}$ & $\begin{array}{l}\text { Communication } \\
\text { Strategies }\end{array}$ & Investment & Key Lessons Learned \\
\hline \multirow{3}{*}{ 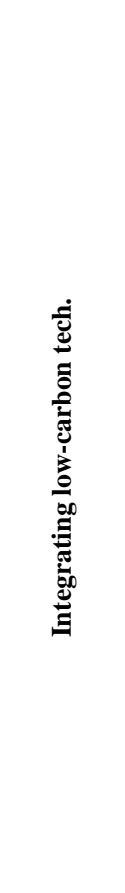 } & Sola Bristol & $\begin{array}{l}\text { Western } \\
\text { Power } \\
\text { Distribution }\end{array}$ & Bristol & $\begin{array}{l}2011- \\
2016\end{array}$ & $\begin{array}{l}\text { Assessing } \\
\text { feasibility of } \\
\text { integrating low- } \\
\text { carbon tech. } \\
\text { using new } \\
\text { technologies } \\
\text { and storage } \\
\text { management }\end{array}$ & $\begin{array}{l}61 \\
\text { homes }\end{array}$ & $\begin{array}{l}\cdot \text { Sunshine tariff }(\mathrm{ToU}) \\
\cdot \mathrm{PV} \text {, energy storage, DC } \\
\text { circuits }\end{array}$ & $\begin{array}{l}\text { Home display, } \\
\text { community engagement, } \\
\text { website }\end{array}$ & $£ 2.8$ million & $\begin{array}{l}\text { - Understanding of } \\
\text { customers" use of energy to } \\
\text { maximise and tune energy } \\
\text { management } \\
\text {-Possible savings for } \\
\text { customers } \\
\text {-Demonstrate the benefits of } \\
\text { deploying DR aggregation } \\
\text { through in-home Multi } \\
\text { energy asset }\end{array}$ \\
\hline & $\begin{array}{l}\text { My Electric } \\
\text { Avenue }\end{array}$ & $\begin{array}{l}\text { Scottish and } \\
\text { Southern } \\
\text { Energy }\end{array}$ & Across UK & $\begin{array}{l}2013- \\
2015\end{array}$ & $\begin{array}{l}\text { Directly control } \\
\text { EVs to manage } \\
\text { local LV } \\
\text { network }\end{array}$ & - & $\begin{array}{l}\text { Lease on EV at a reduced } \\
\text { rate, free/minimal cost } \\
\text { charging point installation, } \\
\text { Esprit (innovative piece of } \\
\text { technology for directly } \\
\text { controlling EV charging) }\end{array}$ & $\begin{array}{l}\text { Local community event } \\
\text { and engagement, } \\
\text { newsletter, social media }\end{array}$ & $£ 9$ million & $\begin{array}{l}\text { - Need of intervention with } \\
\text { increase in the penetration of } \\
\text { Evs } \\
\text { - Forecast of around } £ 2.2 \\
\text { billion savings by } 2050\end{array}$ \\
\hline & $\begin{array}{l}\text { Multi asset } \\
\text { demand } \\
\text { execution } \\
\text { (MADE) }\end{array}$ & $\begin{array}{l}\text { Western } \\
\text { Power } \\
\text { Distribution }\end{array}$ & $\begin{array}{l}\text { South West, } \\
\text { South } \\
\text { Wales,West } \\
\text { midlands, } \\
\text { East } \\
\text { Midlands }\end{array}$ & $\begin{array}{l}2019- \\
2020\end{array}$ & $\begin{array}{l}\text { Providing } \\
\text { higher DR } \\
\text { services } \\
\text { through } \\
\text { multiple energy } \\
\text { assets at } \\
\text { household level }\end{array}$ & $\begin{array}{l}5 \\
\text { homes }\end{array}$ & $\begin{array}{l}\cdot \text { EVs, } \\
\cdot \text { Hybrid heating systems } \\
\cdot \text { Solar PV }\end{array}$ & $\begin{array}{l}\text { Website, Direct } \\
\text { communication }\end{array}$ & $£ 1.655$ million & $\begin{array}{l}\text {-Possible savings for } \\
\text { customers } \\
\text {-Demonstrate the benefits of } \\
\text { deploying DR aggregation } \\
\text { through in-home Multi } \\
\text { energy asset }\end{array}$ \\
\hline
\end{tabular}


DR Infrastructures refer to initial requirements and advanced technologies for enabling DR services for households. In order to efficiently utilize the smart and postponable appliances and local energy generations, which are consider as flexibility resources, end-users need to be equipped with energy consumption monitoring and control devices. One of the key prerequisites is smart metering devices that increase LV visibility by enabling a dynamic and bi-directional data communication in near real-time between consumers and network entities [265]. However, the installation of these devices has faced several economical and technical challenges.

In GB, the initial rollout plan of smart meters by 2020 has now been re-scoped to 2024. Customers widely experienced functionality failures in the original smart meters (first generation) particularly when switching between energy suppliers [266]. Moreover this version of smart meter is not compatible with all types of PV cells. These issues were resolved in the second generation meters [267], first introduced in 2018. The old-type meters have to be upgraded, and this can be done remotely [268]. In addition, smart meters cannot be connected to about $30 \%$ of households due to poor internet connectivity causing communication difficulties between in home-display and smart meters. Therefore, further investigation is warranted to come up with alternative solutions to overcome these communication issues. Nevertheless, it is predicted that $4.5 \%$ of households may not been able to access smart meters due to the solutions being extremely expensive [267]. A report by trade body Energy UK warns the Department for Business, Energy and Industrial Strategy (BEIS) that despite the 2024 extension, in the best case scenario, only $68 \%$ of the targeted $85 \%$ can be achieved [269]. The amount and accuracy of data that is needed to achieve an acceptable level of profile estimation is yet to be determined.

Despite the challenges, the rollout of smart meters can facilitate innovative and new ways of active engagement of consumers in the energy market. The participation of consumers in DR programmes can be done manually through e.g. in-home display or automatically through HEMS. However, moving towards a smart and digital future, energy providers are seeking to model dynamic electricity tariffs to mitigate network constraints in real time. This requires a fast and dynamic response of consumers using HEMS.

On the other hand, the literature undertaken in recent years shows the significant role of aggregators in enabling extensive DR market from local load/generation at LV level that are individually too small for playing an active role in the markets. Aggregators can enhance the network reliability by providing aggregated loads independent from energy suppliers or geographical area that are run by various DSOs. However, the integration of smart assets with customer's ownership to the grid requires a standardized "physical" connection to maintain network stability and reliability. It also requires monitoring and control functionalities at network's level.

Implementation of energy management system and demand side response can be delayed or paused if suitable infrastructure and communication protocols and transmission are not put in place. Inevitably, energy providers, market and SOs need to facilitate appropriate gateway and interfaces to be integrated to flexibility providers at lowvoltage level. The focus of most of the research studies and innovation pilots are on commercial framework for aggregators and flexibility providers. There is less investigation on enabling the market, digitalization platforms and coordination between DSO, transmission SOs and independent aggregators.

A comprehensive review by M. Andoni et. al. [270] shows a considerable interest in literature on using recent technologies such as Blockchain and IoT platforms for digitalization. Blockchain can provide a secure and standardize data communication platform for the interaction of intelligent and smart devices at both network and customers levels. They can also be used in P2P and local energy trading. However, these findings are still in a very 
early stage and further investigations along with practical case studies are needed to prove that the model can be used in a decentralized, scalable, secure and economically viable way.

However, several factors still need to be addressed by SOs and energy regulators and these include the modeling of aggregators by DSOs, the suitability of industry standard and the role of aggregators in the energy markets. In addition, the market model should ensure a level playing field for all network entities with defined and clear role/responsibilities. This includes a solution design architecture with end to end data exchange model in a multiagent system which can model the interaction of all entities. Despite significant recent studies on providing DR models through a MAS framework, there are still limitations in terms of scalability, adoptability, network constraints, DR scenarios and types of agents. Hence, there is a need to develop a coordinated model that considers the interest and objective of each individual type of network entity (agent) in a decentralized platform. In order to enhance the reliability of the network, a combination of incentive-based and price-based DR is also desired to be included in the DR model [171].

However to accommodate these new innovations and technologies, the required infrastructural changes in the conventional electricity network will necessitate a considerable financial investment [271]. This creates the issue of where the responsibility lies for setting up these arrangements [272]. Authors in [273] have referred to this concern as an incentive-problem and suggested that the cost of installations should be shared among network entities so that all DR participants can benefit from this service. What is clear is that a harmonized partnership between public and private sectors is needed to enable the research work in a real-environment.

Consumer Engagement is the key to success for DR implementation. Lack of adequate awareness about the advantages of these programmes as well as inexperience in using these new technologies are the main issues. Some projects have been trialed on a small scale of energy consumers aiming to encourage them to change their sustained behaviour. Moreover, low amount of incentives are offered to households with small DR capacity. Customers should be equipped with PV and plug-in EV (PEV) that provide more flexibility and hence fair economic benefit. More focus is recommended on localized approaches to consider DR within a local community through the use of userfriendly software applications and tools to raise customer awareness. Market rules and competitive rewards schemes can be extended to local communities where each community can get incentives for the reduction within that community.

However, some studies [274] show that even if consumers have high attitudes towards participating in DR programmes, they can still encounter some challenges. For instance, controlling the energy usage all day long is not practically possible for end-users even though home energy displays can make them aware of their electricity consumption and price. HEMS can solve this problem to a certain extent. The load scheduling can be programmed automatically taking into account network constraints and users' comfort level.

Besides education, awareness and incentives, data privacy and security are also major challenges. In GB the smart meter data is available to energy providers, SO and third parties through a central database, DCC. This requires policies and regulations that guarantee safety, security and liability of data exchange.

Technical Concerns are more significant for residential consumers due to the complexity of determining the accurate amount of available DR. This is because of the sporadic and unpredictable nature of domestic loads. Some external factors such as social events and weather conditions can also affect the consumption behavior of users [275]. 
To mitigate these issues, uncertainties in demand and generation should be considered in improving forecasting techniques at distribution level. This will help DR service providers to plan more accurately their actions [274].

Another concern is the peak rebound where a new peak can occur due the high number of demands shifting from peak to non-peak time. A coordinated DR algorithm and control mechanism is required to prevent such issues and thus enhance the network reliability [87]. In addition, the complexity issues arising from the huge data interaction in the network along with characteristics such as types of information and data transfer rate are among the key challenges faced by DSOs and energy providers.

Most of the proposed DR strategies relies on the implementation of HEMS to optimize home energy consumption. HEMS can schedule appliances that consume power in adjustable timeslots where their operations can be stopped, adjusted, or shifted to other timeslots. Based on such an energy management mechanism, HEMS proposed in studies can be categorized as conventional, advanced and smart. The optimization algorithm of the former is based on exclusively load management in response to a price signal e.g. [276-279] whereas the second group considers the price prediction e.g. [182, 280-281]. The latter applies Machine Learning techniques, AI and data-driven algorithms to DR strategies [282-283]. The principles of DR mechanisms in advanced and smart HEMS are fundamentally similar to the conventional HEMS, but are embedded with some sort of intelligence to improve the DR optimisation performance. The recent studies in this field show a considerable interest on the last category by applying AI solutions. AI is the preferred choice for residential level as it can provide an automated decision-making mechanism considering various customers' characteristics, energy usage, preferences and comfort level.

AI can also address the various challenges introduced so far in this paper, related to complexity of LV network, by improving the forecasting of demand, generation and electricity price, big data management, and performance and accuracy of optimisation algorithms at both customer and network levels. However most of the studies on AI applications are limited to a small scale data and simulation environment. Hence, further investigations and real-case scenarios need to be conducted in order to determine the most appropriate techniques in AI for different optimisation purposes.

\section{Conclusion}

The traditional role of DNOs' are now transforming to a DSO one due to changes and challenges within the modern electricity network. This provides facilities for wider implementation of DR to manage network constraints as a less-costly alternative solution to upgrading the network infrastructure. This paper provides a comprehensive review of the relevant researches and trials in GB on the residential DR mechanisms, targets, solutions and applications in managing DNs.

The DR objective function is investigated in terms of both economic and technical targets for both LV and MV feeders. Hence, the focus of this work is on the network level where the main stakeholders are consumers, DSOs, energy suppliers and aggregators. The DR applications and control strategies in microgrids are also reviewed. The outcomes of both literature and pilots demonstrated that DR can be an effective, reliable and economic alternative solution to network upgrading.

The challenges and obstacles faced by DR implementation are also explored from financial, social and technical perspectives. It is also shown that consumer engagement is one of the most important requirements for the success of implementing DR. Considering the various individual characteristics of consumers in algorithms and 
methodologies, can provide the DSOs with a better understanding of available flexibility demands for future planning.

In this work the authors reviewed 226 papers and have identified limitations in the proposed DR implementations. There is still a need for comprehensive frameworks in wide-area networks to model the interaction among participants under real time environments. Most proposed platforms focused solely on one aspect of the DR targets, either the technical target where the aim of DR algorithms is to manage the power flow across the network, or the economic target intended at minimizing electricity cost. This gap can be addressed by including both the technical and economic aspects in DR control schemes.

It has been discussed in the paper that residential consumers have intermittent energy consumption characteristics. This requires the consideration of a more direct approach in peak demand curtailment along with price-based DR as a means of demand-supply support. Very few studies have so far explored the combination of both incentive-based and price-based DR mechanisms in their algorithms and implementations. A distributed intelligent platform can activate the opportunities for residential flexible loads shifting and shedding that include both DR mechanisms.

Our review also presented the relevant innovative pilots in residential DR implementation trialed in GB network. One of the key findings is that the role of local community in providing flexible demand and network support is getting more prominent. Due to the individual low flexible load at residential level, flexibility services provided through DR aggregators seems to be more practical to provide technical support to the network. However, the thorough quantification of potential and available responsive demands and their effectiveness in managing the network under real time is still needs further investigation.

Our work has shown that the future of DR implementation is trending towards the use of new data driven technologies such as AI and Blockchain and P2P energy transaction. Although these are slowly becoming well established, there is still the need for more in-depth research to find optimal solutions for the challenges discussed in this paper. Researches and pilot projects are inexorably paving the way for these techniques to play a leading role in the future of DR implementation.

\section{REFERENCES}

[1] HM Government United Kingdom. Climate change act 2008. UK; 2008. https://www.legislation.gov.uk/ukpga/2008/27/contents. [Accessed 2 December 2019].

[2] Bray R, Woodman B. Barriers to Independent Aggregators in Europe, University of Exeter, 2019. https://geography.exeter.ac.uk/media/universityofexeter/schoolofgeography/images/researchgroups/ epg/Barriers to Independent Aggregators in Europe.pdf.

[3] Committee on Climate Change. Meeting Carbon Budgets - Progress in reducing the UK's emissions. UK; June 2015. https://www.theccc.org.uk/wp-content/uploads/2015/06/6.737_CCCBOOK WEB 030715_RFS.pdf.

[4] Kerahroudi SK, Li F, Bradley ME, Ma Z, Alamuti MM, Rabbani R, Abbod M, Taylor G. Critical evaluation of power system stability enhancement in the future GB transmission using an embedded HVDC link. In: Proceeding of the 11th IET International Conference on AC and DC Power Transmission; 2015. https://doi.org/10.1049/cp.2015.0066

[5] The Department of Energy and Climate Change. UK Renewable Energy Roadmap; July 2011. https://assets.publishing.service.gov.uk/government/uploads/system/uploads/attachment_data/file/4 8128/2167-uk-renewable-energy-roadmap.pdf.

[6] Dietrich K, Latorre JM, Olmos Luis, Ramos Andres, Adequate regulation reserve levels in systems with large wind integration using demand response. Comillas Pontifical University, 2017. 
http://citeseerx.ist.psu.edu/viewdoc/download?doi=10.1.1.709.8893\&rep=rep1\&type=pdf. [Accessed 27 December 2019].

[7] Guidehouse. Growing Global Residential Demand Response Industry; April 2019. https://guidehouse.com/insights/energy/2019/growing-global-residential-demand-response [Accessed 1 July 2020].

[8] Joint Research Centre (JRC) Science for Policy report. Demand Response status in EU Member States; 2016. https://publications.jrc.ec.europa.eu/repository/bitstream/JRC101191/ldna27998enn.pdf. [Accessed 1 July 2020].

[9] Department for Business, Energy and Industrial Strategy (BEIS), Energy Consumption in the UK; 2016 https://www.andrew-lucas.com/wp-content/uploads/2016/12/ECUK 2016.pdf. [Accessed 15 January 2020].

[10] Joint Research Centre (JRC) Science for Policy report. Energy efficiency status report 2012; 2012. https://setis.ec.europa.eu/sites/default/files/reports/energy-efficiency-status-report-2012.pdf. [Accessed 20 January 2020].

[11] Akmal M, Fox B, Morrow DJ, Littler T. Impact of heat pump load on distribution networks. IET Gener. Transm. Distrib 2014;8:2065-73. https://doi.org/10.1049/iet-gtd.2014.0056.

[12] National Grid. Electric dreams: The future for EVs. UK; 2017. https://www.nationalgrid.com/group/case-studies/electric-dreams-future-evs. [Accessed 20 February 2020].

[13] Frontier Economics Ltd. Pathways to high penetration of heat pumps. London; October 2013. https://www.theccc.org.uk/wp-content/uploads/2013/12/Frontier-Economics-Element-EnergyPathways-to-high-penetration-of-heat-pumps.pdf.

[14] Hayes BP, Hernando-Gil I, Collin A, Djokic SZ, Optimal power flow for maximizing network benefits from demand-side management. IEEE Trans Power Syst 2014; 29:1739-47. https://doi.org/10.1109/TPWRS.2014.2298894.

[15] Haider HT, See OH, Elmenreich W. A Review of Residential Demand Response of Smart Grid. J Renew Sust Energ Rev; 2016. 59:166-78. https://doi.org/10.1016/j.rser.2016.01.016.

[16] Shareef H, Ahmed MS, Mohamed A, Hassan EA. Review on home energy management system considering demand responses, smart technologies, and intelligent controllers. IEEE Access J 2018;6:24498-509. https://doi.org/10.1109/ACCESS.2018.2831917.

[17] Khorram M, Faria P, Vale Z. Optimization-based home energy management system under different electricity pricing schemes. In: Proceeding of the 16th IEEE Int. Conference on Industrial Information (INDIN); 2018. https://doi.org/10.1109/INDIN.2018.8472101.

[18] Vega AM, Santamaria F, Rivas E. Modeling for home electric energy management: A review. J Renew Sust. Energ. Rev 2015;52:948-59. https://doi.org/10.1016/j.rser.2015.07.023.

[19] Abubakar I, Khaild SN, Mustafa MW, Sharee H, Mustapha M. Application of load monitoring in appliances' energy management- A review," J. Ren Sust Energ Rev 2017;67:235-45. https://doi.org/10.1016/j.rser.2016.09.064.

[20] Molla T, Khan B, Sign P. A comprehensive analysis of smart home energy management optimization techniques," J Autonomous Intelligence 2018; 1. https://doi.org/10.32629/jai.v1i1.14.

[21] Boodi A, Beddia K, Benamour M, Amirat Y, Benbouzid M. Intelligent Systems for Building energy and occupant comfort optimization: A state of the art review and recommendations. Energies $\mathbf{J}$ 2018;11:1-26.

https://econpapers.repec.org/scripts/redir.pf?u=https\%3A\%2F\%2Fwww.mdpi.com\%2F19961073\%2F11\%2F10\%2F2604\%2Fpdf;h=repec:gam:jeners:v:11:y:2018:i:10:p:2604-:d:172901.

[22] Qayyum N, Amin A, Jamil U, Mahmood A. Optimization techniques for home energy management: A review. In: Proceeding of the 2nd International Conference on Computing, Mathematics and Engineering Technologies (iCoMET). Pakistan; January 2019. https://doi.org/10.1109/ICOMET.2019.8673435.

[23] Patel K, Khosla A. Home energy management systems in future Smart Grid networks: A systematic review. In: Proceeding of the 1st International Conference on Next Generation Computing Technologies (NGCT). Dehradun. INDIA; September 2015. https://arxiv.org/abs/1306.1137.

[24] Antonopoulos I, Robu V, Couraud B, Kirli D, Norbu S, Kiprakis A, Flynn David, ElizondoGonzalez S, Wattam S. Artificial intelligence and machine learning approaches to energy demand- 
side response: A systematic review, J Ren Sust Energ Rev 2020;130:1-35.

https://doi.org/10.1016/j.rser.2020.109899.

[25] Engerati. UK networks: Making the switch from DNO to DSO; 2017.

https://www.engerati.com/article/uk-networks-switch-dno-dso-western-power-distribution. [Accessed 10 Jul. 2017].

[26] Energy Networks Association (ENA). TSO-DSO Project - Forward Plan for Work. London. UK; 2017. https://www.energynetworks.org/assets/files/electricity/futures/Open_Networks/TSODSO\%20Project\%20Framework\%20v6.pdf.

[27] Committee on Climate Change. Net Zero: The UK's contribution to stopping global warming. Committee on Climate Change. UK; May 2019. https://www.theccc.org.uk/wpcontent/uploads/2019/05/Net-Zero-The-UKs-contribution-to-stopping-global-warming.pdf.

[28] Regen Transforming Energy. Smart Grids and the role of the DSO ;2018. https://www.regensw.co.uk/smart-grids-and-the-role-of-the-dso. [Accessed 08 January 2018].

[29] Jenkins N, Long C, Wu J. An Overview of the Smart Grid in Great Britain. Engineering J 2015;4:413-421. https://doi.org/10.15302/J-ENG-2015112.

[30] Siano P. Demand response and smart grids -A survey. J Ren Sust Energ Rev 2014;30:461-78. https://doi.org/10.1016/j.rser.2013.10.022.

[31] Kanga BO, Lee M, Kim Y, Jung J. Economic analysis of a customer-installed energy storage system for both self-saving operation and demand response program participation in South Korea. $\mathbf{J}$ Renew Sust Energ Rev 2018;94:69-83. https://doi.org/10.1016/j.rser.2018.05.062.

[32] Imani MH, Ghadi MJ, Ghavidel S, Li 1. Demand response modeling in microgrid operation: a review and application for incentive-based and time-based programs. J Renew Sust Energ Rev 2018;94:486-499. https://doi.org/10.1016/j.rser.2018.06.017.

[33] Srivastava A, Passel SV, LAes E. Assessing the success of electricity demand response programs: A meta-analysis. Energy Research \& Social Sci J 2018;40:110-117. https://doi.org/10.1016/j.erss.2017.12.005

[34] Paterakis NG, Erdic O, Catalao JPS. An overview of Demand Response: Key-elements and international experience. J Renew Sust Energ Rev 2017;69:871-891. https://doi.org/10.1016/j.rser.2016.11.167.

[35] Weck MHJ, Hooff JV, Sark WGJHMV. Review of barriers to the introduction of residential demand response: a case study in the Netherlands. International J Energy Research 2017;41:790816. https://doi.org/10.1002/er.3683.

[36] Gooda N, Ellis KA, Mancarella P. Review and classification of barriers and enablers of demand response in the smart grid, J Renew Sust Energ Rev, 2017;72:57-72. https://doi.org/10.1016/j.rser.2017.01.043.

[37] European Commission. Q\&A on the European Parliament's vote on the Third Internal Energy Market Legislative Package; April 2009. https://ec.europa.eu/commission/presscorner/detail/en/MEMO 09_176. [Accessed $10 \mathrm{Jul}$. 2020].

[38] Department for Energy and Climate Change. Smart metering implementation programme. Fourth Annual Report on the Roll-out of Smart Meters. UK; November 2015. https://assets.publishing.service.gov.uk/government/uploads/system/uploads/attachment_data/file/4 77258/Smart_Meters_Implementation_Programme_Annual_Report_2015.pdf.

[39] World Economic Forum. The future of electricity new technologies transforming the grid edge; March 2017. http://www3.weforum.org/docs/WEF_Future_of_Electricity_2017.pdf.

[40] Wang Y, Chen Q, Hong T, Kang C. Review of Smart Meter Data Analytics: Applications, Methodologies, and Challenges. IEEE Trans Smart Grid 2019;10:3125-48. https://doi.org/10.1109/TSG.2018.2818167.

[41] Beckel C, Sadamori L, Staake T, Santini S. Revealing household characteristics from smart meter data. Energy 2014;78:397-410. https://doi.org/10.1016/j.energy.2014.10.025.

[42] Yang C, Cheng Q, Lai P, Liu J, Guo H. Data-driven modeling for energy consumption estimation. In: Green energy and technology. Cham: Springer; 2018. https://doi.org/10.1007/978-3-319-625751 72.

[43] Hopf K, Sodenkamp M, Kozlovkiy I, Staake T. Feature extraction and filtering for household classification based on smart electricity meter data Computing Sci Res Develop 2016;31:141-148. http://DOI:10.1007/s00450-014-0294-4. 
[44] Kwac J, Flora J, Rajagopal R. Household energy consumption segmentation using hourly data. IEEE Trans. Smart Grid 2014;5:420-30. https://doi.org/10.1109/TSG.2013.2278477.

[45] Azaza M, Wallin F. Smart meter data clustering using consumption indicators: Responsibility factor and consumption variability. Energy Procedia 2017;142:2236-42. https://doi.org/10.1016/j.egypro.2017.12.624.

[46] Toloo M, Keshavarz E, Hatami-Marbini A. Selecting data envelopment analysis models: A datadriven application to EU countries. Omega 2020; In press. https://doi.org/10.1016/j.omega.2020.102248.

[47] Chen Y, Tan H, Berardi U. A data-driven approach for building energy benchmarking using the Lorenz curve. Energy Build 2018;169: 319-31. https://doi.org/10.1016/j.enbuild.2018.03.066.

[48] Kavousian A, Rajagopal R, Fischer M. Ranking appliance energy efficiency in households: Utilizing smart meter data and energy efficiency Frontiers to estimate and identify the determinants of appliance energy efficiency in residential buildings. Energy Build 2015;99:220-30. https://doi.org/10.1016/j.enbuild.2015.03.052.

[49] Afzalan M, Jazizadeh F. Residential loads flexibility potential for demand response using energy consumption patterns and user segments. Appl energy 2019;254:1136-93. .https://doi.org/10.1016/j.apenergy.2019.113693.

[50] Candanedo LM, Feldheim V, Deramaix D. Data driven prediction models of energy use of appliances in a low-energy house. Energy Build 2017;140:81-97. https://doi.org/10.1016/j.enbuild.2017.01.083.

[51] Guillaume LR, Pinson P, Pierre; Larsen ME. Data-driven Demand Response Characterization and Quantification. In: Proceeding of the 12th IEEE International Conference Power and Energy Society PowerTech; 2017. https://backend.orbit.dtu.dk/ws/portalfiles/portal/133982315/QuantifyDRFull_submit.pdf.

[52] Kapetanakis DS, Nequ O, Finn DP. Prediction of Residential Building Demand Response Potential Using Data-Driven Techniques. In: International Building Performance Simulation Association; 2017. https://www.researchgate.net/profile/DimitriosStavros Kapetanakis/publication/321134464 Prediction of Residential Building Demand Respo nse_Potential_Using_Data-Driven_Techniques/links/5a536461a6fdccf3e2df27af/Prediction-ofResidential-Building-Demand-Response-Potential-Using-Data-Driven-Techniques.pdf.

[53] Subramanian V, Das TK, Kwon FC, Gosavi A. A Data-Driven Methodology for Dynamic Pricing and Demand Response in Electric Power Networks. Electric Power Systems Research 2019;174:1058-69. https://doi.org/10.1016/j.epsr.2019.105869.

[54] Barbato, A. Capone, M. Rodolfi, and D. Tagliaferri. Forecasting the usage of household appliances through power meter sensors for demand management in the smart grid. In Proceeding of the 2011 IEEE International Conference Smart Grid Communications (SmartGridComm). Belgium; 2011. https://doi.org/10.1109/SmartGridComm.2011.6102356.

[55] Lachut D, Banerjee N, Rollins S. Predictability of energy use in homes. In: IEEE International Green Computing Conference; 2014. USA. https://doi.org/10.1109/IGCC.2014.7039146.

[56] Babar M, Nguyen PH, Ćuk V, Kamphuis IG, Bongaerts M, Hanzelka Z. The Evaluation of Agile Demand Response: An Applied Methodology. IEEE Trans Smart Grid 2018;9:6118-27. https://doi.org/10.1109/TSG.2017.2703643.

[57] Lehman J, Chen J, Clune, Stanley KO. Safe Mutations for Deep and Recurrent Neural Networks through Output Gradients. In: Proceeding of the Genetic and Evolutionary Computation Conference. Japan; 2018. https://arxiv.org/pdf/1712.06563.pdf.

[58] Bahrami S, Wong VWS, Huang J. An Online Learning Algorithm for Demand Response in Smart Grid. IEEE Trans Smart Grid 2018;9:4712-25. https://doi.org/10.1109/TSG.2017.2667599.

[59] Claessens BJ, Vrancx, Ruelens F. Convolutional Neural Networks for Automatic State-Time Feature Extraction in Reinforcement Learning Applied to Residential Load Control. IEEE Trans Smart Grid 2018;9:3259-69. https://doi.org/10.1109/TSG.2016.2629450.

[60] Liu D, Sun Y, Qu Y, Li B, Xu Y. Analysis and accurate prediction of user's response behavior in incentive-based demand response. IEEE Access 2019;7:3170-80. https://doi.org/10.1109/ACCESS.2018.2889500. 
[61] Silva IRSD, Rabêloa RAL, Rodrigues JJPC, Solic P, Carvalho A. Preference-based based demand response mechanism for energy management in a microgrid. J Clean Prod 2020;255:1200-34. https://doi.org/10.1016/j.jclepro.2020.120034.

[62] Jiang T. Multi-objective optimal scheduling method for regional photovoltaic-storage-charging integrated system participating in demand response. In: Proceeding of the 8th Renewable Power Generation Conference (RPG). China; October 2019. https://doi.org/10.1049/cp.2019.0383.

[63] Lu R, Hong SH. Incentive-based demand response for smart grid with reinforcement learning and deep neural network. Appl Energy 2019;236:937-49. https://doi.org/10.1016/j.apenergy.2018.12.061.

[64] Zheng W, Wu W, Zhang B, Sheng W. Optimal residential demand response considering the operational constraints of unbalanced distribution networks. In: Proceeding IEEE Power \& Energy Society General Meeting; May 2017. https://doi.org/10.1109/PESGM.2017.8273896.

[65] Albert A, Rajagopal R. Finding the right consumers for thermal demand-response: An experimental evaluation. IEEE Trans Smart Grid 2018;9:564-72. https://doi.org/10.1109/TSG.2016.2555985.

[66] Joseph S, Abdu JE. Real-time retail price determination in smart grid from real-time load profiles. International Trans Elect Energy Syst 2018;28:1-11. https://doi.org/10.1002/etep.2509.

[67] Bedi G, Venayagamoorthy GK, Singh R, Brooks RR, Wang K-C. Review of Internet of Things (IoT) in electric power and energy systems. IEEE Internet of Things J 2018;5:847-70. https://doi.org/10.1109/JIOT.2018.2802704.

[68] Siapartners. Peer-to-peer (P2P) energy : A threat or an opportunity for traditional suppliers ?; 2018. https://www.sia-partners.com/en/news-and-publications/from-our-experts/peer-peer-p2p-energythreat-or-opportunity-traditional. [Accessed 1 August 2020].

[69] Zhou Y, Wu J, Long C. Evaluation of peer-to-peer energy sharing mechanisms based on a multiagent simulation framework. Appl Energy 2018;222:993-1022. https://doi.org/10.1016/j.apenergy.2018.02.089.

[70] Liu W, Qi D, Wen F. Intraday Residential Demand Response Scheme Based on Peer-to-Peer Energy Trading. IEEE Transactions on Industrial Informatics 2020;16:1823-35. https://doi.org/10.1109/TII.2019.2929498.

[71] Rao BH, Arun SL, Selvan MP. Framework of locality electricity trading system for profitable peerto-peer power transaction in locality electricity market. IET Smart Grid 2020;3:318-30. https://doi.org/10.1049/iet-stg.2019.0131.

[72] Rao BH, Arun SL, Selvan MP. An electric power trading framework for smart residential community in smart cities. IET Smart Cities 2019;1:40-51. https://ieeexplore.ieee.org/stamp/stamp.jsp?arnumber=8957774.

[73] Zhang C, Wu J, Zhou Y, Cheng M, Long C. Peer-to-peer energy trading in a microgrid. Appl Energy 2018;220:1-12. https://orca.cf.ac.uk/109995/10/1\%20Peer-topeer\%20energy\%20trading\%20in\%20a\%20microgrid.pdf.

[74] Liu N, Yu X, Wang C, Li C, Ma L, Lei J. Energy-sharing model with price-based demand response for microgrids of peer-to-peer prosumers. IEEE Trans Power Syst 2017;32(5):3569-83. https://doi.org/10.1109/TPWRS.2017.2649558.

[75] Long C, Wu J, Zhou Y, Jenkins N. Peer-to-peer energy sharing through a two-stage aggregated battery control in a community microgrid. Appl Energy 2018;226:261-76. http://10.1016/j.apenergy.2018.05.097.

[76] Luth A, Zepter JM, del Granado PC, Egging R. Local electricity market designs for peer-to-peer trading: the role of battery flexibility. Appl Energy 2018;229:1233-43. https://doi.org/10.1016/j.apenergy.2018.08.004.

[77] Alam MR, St-Hilaire M, Kunz T. Peer-to-peer energy trading among smart homes. Appl Energy 2019;238. 1434-43. https://doi.org/10.1016/j.apenergy.2019.01.091.

[78] Zhang Z, Tang H, Wang P, Huang Q, Lee QJ. Two-Stage Bidding Strategy for Peer-to-Peer Energy Trading of Nanogrid. IEEE Transactions on Industry Applications 2020;56:1000-9. https://doi.org/10.1109/TIA.2019.2958302.

[79] Zhou Y, Wu J, Long C. Evaluation of peer-to-peer energy sharing mechanisms based on a multiagent simulation framework. Appl Energy 2018;222:993-1022.

https://doi.org/10.1016/j.apenergy.2018.02.089. 
[80] Long C, Wu J, Zhang C, Thomas L, Cheng M, Jenkins N. Peer-to-peer energy trading in a community microgrid. IEEE PES general meeting, USA; 2017. https://doi.org/10.1109/PESGM.2017.8274546.

[81] Venkatesan N, Jignesh S, Solanki SK. Residential demand response model and impact on voltage profile and losses of an electric distribution network. Appl Energy 2012;96:84-91. https://doi.org/10.1016/j.apenergy.2011.12.076.

[82] Carreir P, Nunes R, Amaral V. SmartLink: A Hierarchical Approach for Connecting Smart Buildings to Smart Grids. In: Proceeding of the 11th IEEE International Conferences on Electrical Power Quality and Utilisation; 2011. https://doi.org/10.1109/EPQU.2011.6128857.

[83] Scottish and Southern Energy Power Distribution. Trial evaluation of domestic demand side management. Scotland; October 2012. https://www.smarternetworks.org/project/sset1003. [Accessed 1 August 2020].

[84] Aalami HA, Moghaddam MP, Yousefi GR. Demand response modeling considering Interruptible/Curtailable loads. Appl Energy 2010;87:243-250. https://doi.org/10.1016/j.apenergy.2009.05.041.

[85] Saebi J, Taheri H, Mohammadi J, Nayer SS. Demand bidding/buyback modeling and its impact on market clearing price. In: IEEE International Energy Conference; 2010. https://doi.org/10.1109/ENERGYCON.2010.5771788.

[86] Department of Energy and Climate Change. Implementing Electricity Market Reform (EMR). UK; June 2014. https://assets.publishing.service.gov.uk/government/uploads/system/uploads/attachment_data/file/3 24176/Implementing_Electricity_Market_Reform.pdf. [Accessed 1 August 2020].

[87] Ponnaganti P, Pillai JR, Bak-Jensen B. Opportunities and challenges of demand response in active distribution networks. WIREs Energy Environ 2018;7:1-16. https://onlinelibrary.wiley.com/doi/abs/10.1002/wene.271.

[88] Tyagi R, Black JW. Emergency demand response for distribution system contingencies. IEEE PES T\&D. New Orleans. USA; 2010. https://doi.org/10.1109/TDC.2010.5484598.

[89] Shao S, Zhang T, Pipattanasomporn M, Rahman S. Impact of TOU rates on distribution load shapes in a smart grid with PHEV penetration. IEEE PES T\&D. USA; 2010. https://doi.org/10.1109/TDC.2010.5484336.

[90] Imperial College London. Residential consumer responsiveness to time-varying pricing. London, UK; Sept. 2014. https://innovation.ukpowernetworks.co.uk/wp-content/uploads/2019/05/A3Residential-Consumer-Responsiveness-to-Time-varying-Pricing.pdf. [Accessed 1 August 2020].

[91] Faruqui A, Hledik R, Sergici S. Piloting the smart grid Elect J 2009:22:55-69. https://doi.org/10.1016/j.tej.2009.06.012.

[92] Ashouri A, Stadler P, Maréchal F. Day-ahead promised load as alternative to real-time pricing, In: IEEE International Conference on Smart Grid Communications (SmartGridComm). USA; 2015. https://doi.org/10.1109/SmartGridComm.2015.7436358.

[93] Chapman AC, Verbic G, Hill DJ. Algorithmic and strategic aspects to integrating demand-side aggregation and energy management methods. IEEE Trans Smart Grid 2016;7:2748-60. https://doi.org/10.1109/TSG.2016.2516559.

[94] Losi A, Mancarella P, Vicino A. Integration of demand response into the electricity chain. UK. John Wiley \& Sons; 2015. https://www.wiley.com/engb/Integration+of+Demand+Response+into+the+Electricity+Chain\%3A+Challenges\%2C+Opportu nities\%2C+and+Smart+Grid+Solutions-p-9781848218543.

[95] Origami. Transition analysis of relevant international experience of DSO flexibility markets; August 2019. https://ssen-transition.com/wp-content/uploads/2019/08/TRANSITION-Analysis-of-relevantinternational-experience-of-DSO-flexibility-markets.pdf. [Accessed 1 August 2020].

[96] Davarzani S. Multi Agent System Framework for Demand Response Management in Distribution Networks. London. Brunel University London; June 2018. https://bura.brunel.ac.uk/bitstream/2438/17149/1/FulltextThesis.pdf.

[97] Office of Gas and Electricity Markets (Ofgem). The GB electricity distribution network; 2017. https://www.ofgem.gov.uk/electricity/distribution-networks/gb-electricity-distribution-network. [Accessed 20 December 2019]. 
[98] Office of Gas and Electricity Markets (Ofgem). Compare gas and electricity tariffs: Ofgemaccredited price comparison sites; 2017. https://www.ofgem.gov.uk/consumers/household-gas-andelectricity-guide/how-switch-energy-supplier-and-shop-better-deal/compare-gas-and-electricitytariffs-ofgem-accredited-price-comparison-sites. [Accessed 11 December 2019].

[99] Department Energy Climate Change. Impact assessment of a GB-wide smart meter rollout for the domestic sector. Ofgem; December 2009. https://www.ofgem.gov.uk/ofgempublications/63551/decc-impact-assessment-domesticpdf.

[100] International Risk Governance Council (IRGC). Demand-side flexibility for energy transaction; 2015. https://irgc.org/wp-content/uploads/2018/09/Demand-side-Flexibility-for-Energy-TransitionsPolicy-Brief-2016.pdf.

[101] Data Communication Company (DCC); 2018. https://www.smartdcc.co.uk/about-dcc. [Accessed 10 February 2019].

[102] KPMG/ Vlerick Business School. Outlook on the European DSO Landscape 2020. https://home.kpmg/content/dam/kpmg/pdf/2016/05/Energy-Outlook-DSO-2020.pdf.

[103] Faria P, Spínola J, Vale Z. Aggregation and remuneration of electricity consumers and producers for the definition of demand-response programs. IEEE Trans Indust Informatics 2016;12:952-61. https://doi.org/10.1109/TII.2016.2541542.

[104] Ozturk Y, Jha P, Kumar S, Lee G. A Personalized Home Energy Management. System for Residential Demand Response. In: Proceeding of the 4th Intl conference on power Engineering and electrical drives. Turkey; 2013. https://doi.org/10.1109/PowerEng.2013.6635790.

[105] Li S, Zhang D, Roget AB, O’Neill Z. Integrating Home Energy Simulation and Dynamic Electricity Price for Demand Response Study. IEEE Trans Smart Grid 2014;5:779-88. https://doi.org/10.1109/TSG.2013.2279110.

[106] Rad AHM, Wong WS, Jatskevich J, Schober R, Garcia AL. Autonomous Demand-Side Management Based on Game-Theoretic Energy Consumption Scheduling for the Future Smart Grid. IEEE Trans Smart Grid 2010;1:320-31. https://doi.org/10.1109/TSG.2010.2089069.

[107] Li Y, Ng BL, Trayer M, Liu L. Automated residential demand response: Algorithmic implications of pricing model. IEEE Trans Smart Grid 2012;3:1712-21. https://doi.org/10.1109/TSG.2012.2218262.

[108] Atzeni I, Ordonez LG, Scutari G, Palomar DP, Fonollosa JR. Demand-side management via distributed energy generation and storage optimization. IEEE Trans Smart Grid 2013;4:886-96. https://doi.org/10.1109/TSG.2012.2206060.

[109] Li J, Wu Z, Zhou S, Fu H, Zhang XP. Aggregator service for PV and battery energy storage systems of residential building. CSEE Power and Energ Syst 2015;1:3-11. https://doi.org/10.17775/CSEEJPES.2015.00042.

[110] Meng FL, Zeng XJ. A profit Maximization Approach to Demand Response Management with Customers Behavior Learning in Smart Grid, IEEE Trans Smart Grid 2016;71516-29. https://doi.org/10.1109/TSG.2015.2462083.

[111] Agnetis A, Dellino G, Pascale GD, Innocenti G, Pranzo M, Vicino A. Optimization models for consumer flexibility aggregation in smart grids: The ADDRESS approach. 1st International Workshop on Smart Grid Modeling and Simulation (SGMS). Belgium; October 2011. https://doi.org/10.1109/SGMS.2011.6089206.

[112] Pradhan V, Balijepalli VSKM, Khaparde SA. An Effective Model for Demand Response Management Systems of Residential Electricity Consumers. IEEE Syst J 2016;10:434-445. https://doi.org/10.1109/JSYST.2014.2336894.

[113] Vahid-Ghavidel M, Mahmoudi, Mohammadi-ivatloo B. Self-Scheduling of Demand Response Aggregators in Short-Term Markets Based on Information Gap Decision Theory. IEEE Trans Smart Grid 2019;10:2115-26. https://doi.org/10.1109/TSG.2017.2788890.

[114] Lin X, Wang Y, Pedram M. Designing the optimal pricing policy for aggregators in the smart gridGreen Technologies. In: Proceeding of the 6th Annual IEEE Green Technologies Conference (GreenTech). USA; 2014. https://doi.org/10.1109/GREENTECH.2014.28.

[115] Nguyen DT, Le LB. Risk-constrained profit maximization for microgrid aggregators with demand response. IEEE Trans Smart Grid 2015;6:135-46. https://doi.org/10.1109/TSG.2014.2346024. 
[116] Chen Y, Lin WS, Han F, Yang YH, Safar Z. A cheat-proof game theoretic demand response scheme for smart grids. In: IEEE International Conference on Communications. Canada; June 2012. https://doi.org/10.1109/ICC.2012.6364397.

[117] Sarker MR, Vazquez MAO, Kirschen DS. Optimal Coordination and Scheduling of Demand Response via Monetary Incentives. IEEE Trans Smart Grid 2015;6:1341-52. https://doi.org/10.1109/TSG.2014.2375067.

[118] Pedrasa MAA. Spooner TD, MacGill IF. Coordinated scheduling of residential distributed energy resources to optimize smart home energy services. IEEE Trans Smart Grid 2010;1:134-43. https://doi.org/10.1109/TSG.2010.2053053.

[119] Cecati C, Citro C, Siano P. Combined operations of renewable energy systems and responsive demand in a smart grid. IEEE Trans Sustainable Energy 2011;2:468-476. https://doi.org/10.1109/TSTE.2011.2161624.

[120] Sedzro KS, Lamadrid AJ, Chuah MC. Generalized minimax: A self-enforcing pricing scheme for load aggregators. IEEE Transactions on Smart Grid 2018;9:1953-63. https://doi.org/10.1109/TSG.2016.2602870.

[121] Parvania M, Fotuhi-Firuzabad M, Shahidehpour M. Optimal demand response aggregation in wholesale electricity markets. IEEE Trans Smart Grid 2013;4:1957-65. https://doi.org/10.1109/TSG.2013.2257894.

[122] Philbott AB, Pettersen E. Optimizing demand-side bids in day-ahead electricity markets. IEEE Trans Power Syst 2006;21:488-98. https://doi.org/10.1109/TPWRS.2006.873119.

[123] Samadi P, Mohsenian-Rad H, Schober R, Wong VWS. Advanced demand side management for the future smart grid using mechanism design. IEEE Trans Smart Grid 2012;3:1170-80. https://doi.org/10.1109/TSG.2012.2203341.

[124] Dong Q, Song WZ, Tong L, Tang S. Distributed demand and response algorithm for optimizing social-welfare in smart grid. In: 26th International Parallel \& Distributed Processing Symposium (IPDPS). China; 2012. https://doi.org/10.1109/IPDPS.2012.112.

[125] Jiang L, Low S. Multi-period optimal procurement and demand responses in smart grid with uncertain supply. In: Proceeding of the IEEE 50th Conference on Decision and Control and European Control Conference (CDC-ECC). USA; 2011. https://doi.org/10.1109/CDC.2011.6161320.

[126] Doostizadeh M, Ghasemi H. A day-ahead electricity pricing model based on smart metering and demand-side management. Energy J 2012;46:221-30. https://doi.org/10.1016/j.energy.2012.08.029.

[127] Walawalkar R, Blumsack S, Apt J, Fernands S. An economic welfare analysis of demand response in the PJM electricity market. Energy Policy J 2008;36:3692-702. https://doi.org/10.1016/j.enpol.2008.06.036.

[128] Babar M, Nguyen PH, Ćuk C, Kamphuis IG, Bongaerts M, Hanzelka Z. The evaluation of agile demand response: An applied methodology. IEEE Trans Smart Grid 2018;9: 6118-27. https://doi.org/10.1109/TSG.2017.2703643.

[129] Mhanna S, Verbič G, Chapman AC. A faithful distributed mechanism for demand response aggregation. IEEE Trans Smart Grid 2016;7:1743-53. https://doi.org/10.1109/TSG.2015.2429152.

[130] Nijhuis M, Muhammad B, Gibescu M, Cobben S. Demand response: social welfare maximization in an unbundled energy market case study for the low-voltage networks of a distribution network operator in the Netherlands. IEEE Trans Indust App 2017;53:32-38. https://doi.org/10.1109/TIA.2016.2608783.

[131] Salah F, Henríquez R, Wenzel G, Olivares DE. Portfolio design of a demand response aggregator with satisficing consumers. IEEE Trans Smart Grid 2019;10:2475-84. https://doi.org/10.1109/TSG.2018.2799822.

[132] Li Z, Wang S, Zheng X, De León F. Dynamic Demand Response using Customer Coupons Considering Multiple Load Aggregators to Simultaneously Achieve Efficiency and Fairness. IEEE Trans Smart Grid 2018;9:3112-21. https://doi.org/10.1109/TSG.2016.2627140.

[133] Safdarian A, Fotuhi-Firuzabad M, Lehtonen. Optimal residential load management in smart grids: A decentralized framework. IEEE Trans Smart Grid 2016;7:1836-45. https://doi.org/10.1109/TSG.2015.2459753. 
[134] Gkatzikis L, Koutsopoulos I, Salonidis T. The Role of Aggregators in Smart Grid Demand Response Markets. IEEE J on Selected Areas in Communications 2013;31:1247-57. https://doi.org/10.1109/JSAC.2013.130708.

[135] Song P, Xu Z, Luo C, Cai H, Xie Z. Voltage sensitivity analysis based bus voltage regulation in transmission systems with UPFC series converter. In: proceeding of the 43rd Industrial Electronics Society (IECON). China; 2017. https://doi.org/10.1109/IECON.2017.8216085.

[136] Ayón X, Moreno MA, Usaola J. Aggregators' optimal bidding strategy in sequential day-ahead and intraday electricity spot markets. Special Issue Dist Energ Res Management in Energies J 2017;10:1-20. file:///D:/Users/davar1s/Downloads/energies-10-00450\%20(1).pdf.

[137] Liu Y, Guan X. Purchase Allocation and Demand Bidding in Electric Power Markets. IEEE Trans Pow Syst 2003;18:106-112. https://doi.org/10.1109/TPWRS.2002.807063.

[138] Anwar BA, Burke DJ, Malley MJO. A multi-perspective model for evaluation of residential thermal demand response. IEEE Trans Smart Grid 2019;10:5214-27. https://doi.org/10.1109/TSG.2019.2899780.

[139] Shafie-khah M, Catalão JPS. A Stochastic Multi-Layer Agent-Based Model to Study Electricity Market Participants Behavior. IEEE Trans Power Syst 2015;30:867-81. https://doi.org/10.1109/TPWRS.2014.2335992.

[140] Balijepalli VSKM, Khapard SA. A system and method for electricity price forecasting with a Novel Forecast Error Correction. Recent Patents on Electrical \& Electronic Engineering 2013;6:29-41. https://doi.org/10.2174/2213111611306010004.

[141] Karimi H, Jadid S, Saboori H. Multi-objective bi-level optimisation to design real-time pricing for demand response programs in retail markets. IET Gener Transm Distrib 2018;13:1287-96. https://doi.org/10.1049/iet-gtd.2018.6123.

[142] Bruninx K, Pandžić H, Le Cadre H, Delarue E. On the interaction between aggregators, electricity markets and residential demand response providers. IEEE Trans Pow Syst 2019;1:840-53. https://doi.org/10.1109/TPWRS.2019.2943670.

[143] Henríquez R, Wenzel G, Olivares DE, Negrete-Pincetic M. Participation of demand response aggregators in electricity markets: optimal portfolio management. IEEE Trans Smart Grid 2017;9:4861-71. https://doi.org/10.1109/TSG.2017.2673783.

[144] Safdarian A, Fotuhi-Firuzabad M, Lehtonen. A Distributed algorithm for managing residential demand response in smart grids. IEEE Trans Industrial Informatics 2014;10:2385-2393. https://dx.doi.org/10.1016\%2Fj.heliyon.2017.e00457.

[145] Zakariazadeh A, Homaee O, Jadid S, and Siano P. A new approach for real time voltage control using demand response in an automated distribution system. Appl Energy 2014;117:157-66. https://doi.org/10.1016/j.apenergy.2013.12.004.

[146] Richardson P, Flynn D, Keane A. Optimal charging of electric vehicles in low-voltage distribution systems. IEEE Trans Power Syst 2012;27:268-79. https://doi.org/10.1109/TPWRS.2011.2158247.

[147] Viyathukattuva M, Nguyen MAPH, Kling WL. An integrated control for overvoltage mitigation in the distribution network. In: IEEE PES Innovative Smart Grid Technologies Conference Europe. Istanbul. Turkey; October 2014. https://doi.org/10.1109/ISGTEurope.2014.7028903.

[148 Savaghebi M, Jalilian A, Vasquez JC, Guerrero JM. Secondary control scheme for voltage unbalance compensation in an islanded droop-controlled microgrid. IEEE Trans Smart Grid 2012;3:797-807. https://doi.org/10.1109/TSG.2011.2181432.

[149] Vivekananthan C, Mishra Y, Ledwich G, Li F. Demand Response for Residential Appliances via Customer Reward Scheme. IEEE Trans Smart Grid 2014;5:809-820. https://doi.org/10.1109/TSG.2014.2298514.

[150] Tonkoski R, Lopes LAC. Droop-based active power curtailment for overvoltage prevention in grid connected PV inverters. In: IEEE International Symposium on Industrial Electronics (ISIE). Bari. Italy; July 2010. https://doi.org/10.1109/ISIE.2010.5637511.

[151] Etherden N, Bollen MHJ. Overload and overvoltage in low-voltage and medium-voltage networks due to renewable energy_-some illustrative case studies. Electr Power Syst Res 2014;114:39-48. https://doi.org/10.1109/ISGTEurope.2011.6162645.

[152] You S, Segerberg H. Integration of $100 \%$ micro-distributed energy resources in the low voltage distribution network: A Danish case study. Appl Therm Eng J 2014;71:797-808. https://doi.org/10.1016/j.applthermaleng.2013.11.039. 
[153] Liu W, Wu Q, Wen F, Østergaard J. Day-ahead congestion management in distribution systems through household demand response and distribution congestion prices. IEEE Trans Smart Grid 2014;5:2739-47. https://doi.org/10.1109/TSG.2014.2336093.

[154] S Shao, Pipattanasomporn M, Rahman S, An Approach for Demand Response to Alleviate Power System Stress Conditions. In: IEEE Power Energy Soc. Gen. Meeting. USA; 2011. https://doi.org/10.1109/PES.2011.6039852.

[155] Khamphanchai W, Pipattanasomporn M, Rahman S, Al-Awami AT. Impact of electric vehicles on household voltage profiles and possible mitigation approach. In: IEEE PES Innovative Smart Grid Technologies Conference Europe (ISGT-Europe). Istanbul. Turkey; October 2014. https://doi.org/10.1109/ISGTEurope.2014.7028988.

[156] Khamphanchai W, Pipattanasomporn M, Kuzlu M, Zhang J, Rahman S. An Approach for Distribution Transformer Management With a Multiagent System. IEEE Trans Smart Grid 2015;6:1208-18. https://doi.org/10.1109/TSG.2014.2380413.

[157] Haque ANMM, Nguyen HP, Vo T, Bliek F.W. Agent-based unified approach for thermal and voltage constraint management in LV distribution network. Elec Pow Syst Res 2016;143:462-473. https://doi.org/10.1016/j.epsr.2016.11.007.

[158] Degefa MZ, Lehtonen M, Millar RJ, Alahäivälä A, Saarijärvi E. Optimal voltage control strategies for day-ahead active distribution network operation. Electr. Power Syst. Res. 2015, vol. 127, pp. 41-52. https://doi.org/10.1016/j.epsr.2015.05.018.

[159] Vandoorn TL, De Kooning JDM, Meersman B, Vandevelde L. Soft curtailment for voltage limiting in low-voltage networks through reactive or active power droops. In: Proceeding of 2nd IEEE Energycon Conference \& Exhibition. Italy; September 2012. https://doi.org/10.1109/EnergyCon.2012.6348213.

[160] Khamphanchai W, Kuzlu M, Pipattanasomporn M. A smart distribution transformer management with multi-agent technologies. In: IEEE PES Innovative Smart Grid Technologies (ISGT) Conference. USA; February 2013. https://doi.org/10.1109/ISGT.2013.6497791.

[161] Molitor C, Ponci F, Monti A, Cali D, Muller D. Consumer benefits of electricity-price-driven heat pump operation in future smart grids. In: IEEE International Conference Smart Measurements Future Grids (SMFG). Italy; November 2011. https://doi.org/10.1109/SMFG.2011.6125774.

[162] Fonteijn R, Amstel MV, Nguyen P, Morren J, Bonnema GM, Slootweg H. Evaluating flexibility values for congestion management in distribution networks within Dutch pilots. J Engineering 2018;2019:5158-62. https://doi.org/10.1049/joe.2018.9314.

[163] Akhtar Z, Opatovsky M, Chaudhuri B, Hui AYR. Comparison of point-of-load versus mid-feeder compensation in LV distribution networks with high penetration of solar photovoltaic generation and electric vehicle charging stations. IET Smart Grid 2019;2:283-92. https://doi.org/10.1049/ietstg.2018.0193.

[164] Haque ANMM, Nijhuis M, Ye G, Nguyen PH, Bliek FW, Slootweg JG. Integrating direct and indirect load control for congestion management in LV networks. IEEE Trans Smart Grid 2019;10:741-51. https://doi.org/10.1109/TSG.2017.2751743.

[165] Guo J, Chaudhuri B, Hui AYR. Flexible Demand Through Point-of-Load Voltage Control in Domestic Sector. IEEE Trans Smart Grid 2019;10: 4662-72. https://doi.org/10.1109/TSG.2018.2866369.

[166] Mirzaei SMHM, ganji B, Taher SA. Performance improvement of distribution networks using the demand response resources. IET Gen, Trans \& Dist 2018;13:4171-79. https://doi.org/10.1049/ietgtd.2018.6616.

[167] Karthikeyan N, Pillai JR, Bak-Jensen B, Simpson-Porco JW. Predictive control of flexible resources for demand response in active distribution networks," IEEE Trans Power Syst 2019;342957-69. https://doi.org/10.1109/TPWRS.2019.2898425.

[168] Lu J, Chu W, Ren H, He T, Wang F. Coordinated optimal dispatch of multi-stakeholder stakeholder game based on demand response for active distribution network. Special Issue: Demand Side Management and Market Design for Renewable Energy Support and Integration of IEEE Renew Pow Gen 2018;13:898-904. https://doi.org/10.1049/iet-rpg.2018.5589.

[169] Haque ANMM, Nguyen PH, Bliek FW, Slootweg JG. Demand response for real-time congestion management incorporating dynamic thermal overloading cost. Sust Energ Grids and NetJ 2017;10: 65-74. https://doi.org/10.1016/j.segan.2017.03.002. 
[170] Haque ANMM, Rahman M T, Nguyen PH, Bliek FW. Smart curtailment for congestion management in LV distribution network. In: IEEE Power and Energy Society General Meeting (PESGM). USA; July 2016. https://doi.org/10.1109/PESGM.2016.7741936.

[171] Asadinejad A, Tomsovic K. Optimal use of incentive and price based demand response to reduce costs and price volatility. Electr Power Syst Res 2017;144:215-23. https://doi.org/10.1016/j.epsr.2016.12.012.

[172] Csetvei Z, Ostergaard J, Nyeng P. Controlling price responsive heat pumps for overload elimination in distribution system. In: Proceeding of the 2nd IEEE PES International Conference Exhibition Innovation Smart Grid Technol. (ISGT Europe).UK; December 2011. https://doi.org/10.1109/ISGTEurope.2011.6162690.

[173] Moradi MH, Abedini M. Optimal load shedding approach in distribution systems for improved voltage stability. In: Proceeding of the 4th IEEE International Power Engineering and Optimization Conference (PEOCO). Malaysia; June 2010. https://doi.org/10.1109/PEOCO.2010.5559241.

[174] Kumar V, Gupta I, Gupta HO, Agarwal CP. Voltage and current sensitivities of radial distribution network: a new approach. IEEE Gener Transm Distrib 2005;152:813-18. https://doi.org/10.1049/ipgtd:20045068.

[175] Girgis AA, Mathure S. Application of active power sensitivity to frequency and voltage variations on load shedding. Elec Pow Syst Res J 2010;80:306-10. https://doi.org/10.1016/j.epsr.2009.09.013.

[176] Abhiraj TK, Jos BM, Aravindhababu P. Sensitivity based Load Shedding Strategy for Avoiding Voltage Instability. J Electrical Engineering 2017;4:5056-60. https://doi.org/10.18535/IJETST\%2FV4I4.02.

[177] Yu JJQ, Lin J, Lam AYS, Li VOK. Maximizing aggregator profit through energy trading by coordinated electric vehicle charging. In: IEEE International Conference on Smart Grid Communications (SmartGridComm). Australia; 2016. https://doi.org/10.1109/SmartGridComm.2016.7778810.

[178] Choobineh M, Speake A, Harris M, Tabre PC. End-user-aware community energy management in a distribution system exposed to extreme temperatures. IEEE Trans Smart Grid 2019;10:3753-64. https://doi.org/10.1109/TSG.2018.2834572.

[179] Xie J, Liu CC. Multi-agent systems and their applications. International Council Electrical Engineering 2017;7:188-97. https://doi.org/10.1080/22348972.2017.1348890.

[180] Ericson T. Households' self-selection of dynamic electricity tariffs. Appl Energy 2011;88;2541-47. https://doi.org/10.1016/j.apenergy.2011.01.024.

[181] Joo JY, Ilić MD. A Multi-Layered Adaptive Load Management (ALM) System: Information exchange between market participants for efficient and reliable energy use. In: IEEE PES Trans and Dist Conf. New Orleans; June 2010. https://doi.org/10.1109/TDC.2010.5484311.

[182] Wang Z, Paranjape R. Optimal Residential Demand Response for Multiple Heterogeneous Homes With Real-Time Price Prediction in a Multiagent Framework. IEEE Trans Smart Grid 2017;8:117384. https://doi.org/10.1109/TSG.2015.2479557.

[183] Li HA, Nair NKC. Multi-agent systems and demand response: A systematic review. In: IEEE 2015 Australasian Universities Power Engineering Conference (AUPEC). Australia; September 2015. https://doi.org/10.1109/AUPEC.2015.7324827.

[184] Coelho VN, Cohen MW, Coelho IM, Liu N, Guimarães FG. Multi-agent systems applied for energy systems integration: state-of-the-art applications and trends in microgrids. Appl Energy 2017;32: 820-32. https://doi.org/10.1016/j.apenergy.2016.10.056.

[185] Gazafroudi AS, Pinto T, Prieto-Castrillo F, Corchado JM, Abrishambaf O, Jozi A, Vale Z. Energy flexibility assessment of a multi agent-based smart home energy system. In: Proceeding of the 17th IEEE Int Conf on Ubiquitos Wireless Broadband. Spain; 2017. https://doi.org/10.1109/ICUWB.2017.8251008.

[186] Pezeshki H, Wolfs PJ, Johnson M. Multi-agent systems for modeling high penetration photovoltaic system impacts in distribution networks. In: Proceeding of the 2011 IEEE PES Innovative Smart Grid Technologies. Australia; 2011. https://doi.org/10.1109/ISGT-Asia.2011.6167149.

[187] Oliveira P, Pinto T, Morais H, Vale Z. MASGriP - multi-agent smart grid simulation platform. In: Proceedings of the 2012 IEEE Power and Energy Society General Meeting. USA; July 2012. https://doi.org/10.1109/PESGM.2012.6345649. 
[188] Santos G, Pinto T, Praça I, Vale Z. MASCEM: Optimizing the performance of a multi-agent system. Energy J 2016;111:513-524. https://doi.org/10.1016/j.energy.2016.05.127.

[189] Ranjan R, DAS D. Voltage Stability Analysis of Radial Distribution Networks. Electric Power Components and Systems J 2010;31:501-11. https://doi.org/10.1016/S0142-0615(00)00040-5.

[190] Chen Y, Ma G, Wang Y. Real-time price responding method in distribution network based on smart loads. Engineering J 2019; 2019:1087-90. https://doi.org/10.1049/joe.2018.8551.

[191] Lu J, Chu W, Ren H, He T, Wang F. Coordinated optimal dispatch of multi-stakeholder game based on demand response for active distribution network. IET Renewable Power Generation 2019;13:898-904. https://doi.org/10.1049/iet-rpg.2018.5589.

[192] Bhatt DV, Bhatt YH, Pakka VH. Loss Sensitivity and Voltage Deviation Index Based Intelligent Technique for Optimal Placement and Operation of Distributed Generators. In: Proceeding of the 7th IEEE International Conference on Power and Energy (PECon). Malaysia; 2018. https://doi.org/10.1109/PECON.2018.8684177.

[193] Venkateswarlu G, Srikanth K, Ajaykumar T, Gouthamkumar N. Critical load estimation for sensitive node of radial distribution system. Int J of Pure and Applied Mathematics 2017;114:2129. https://acadpubl.eu/jsi/2017-114-7-ICPCIT-2017/articles/7/3.pdf.

[194] Bhat L, Shrivastava A, rudraswamy S. Sensitivity analysis for 14 bus systems in a distribution network with distributed generators. IOSR J Electrical and Electronics Engineering (IOSR-JEEE) 2015;1021-27. https://www.iosrjournals.org/iosr-jeee/Papers/Vol10-issue3/Version1/D010312127.pdf.

[195] Jahan S, Mannan MdAl. Voltage Stability analysis of a 16-bus distribution network based on voltage sensitivity factor. Int J Multidiciplinary Sciand Engineering 2014;5:1-5. http://www.ijmse.org/Volume5/Issue4/paper1.pdf.

[196] Peschon J, Piercy D, Tinney W, Tveit O. Sensitivity in power systems. IEEE Trans Power Apparatus and Syst 1986;PAS-87:1687-96. https://doi.org/10.1109/TPAS.1968.292130.

[197] Shirmohammadi D, Hong H, Semlyen A, Luo G. A compensation-based power flow method for weakly meshed distribution and transmission networks. IEEE Trans Power Syst 1986;3:753-62. https://doi.org/10.1109/59.192932.

[198] Bakhshideh Zad B, Hasanvand H, Lobry cJ, Vallée F. Optimal reactive power control of DGs for voltage regulation of MV distribution systems using sensitivity analysis method and PSO algorithm. Electr Power and Energ Syst J 2015;68:52-60. https://doi.org/10.1016/j.ijepes.2014.12.046.

[199] B. Bakhshideh Zad, Lobry J, Vallee F, Hasanvand H. Optimal reactive power control of DGs for voltage regulation of MV distribution systems considering thermal limit of the system branches. In: Proceeding of the IEEE International Conference Power Syst Tech (POWERCON). China; 2014. https://doi.org/10.1109/POWERCON.2014.6993975.

[200] Gurram R, Subramanyam B. Sensitivity analysis of radial distribution network - adjoint network method. Electr Power Energ Syst 1999;21:323-26. https://doi.org/10.1016/S0142-0615(98)00058-1.

[201] Christakou K, LeBoudec JY, Paolone M, Tomozei DC. Efficient computation of sensitivity coefficients of node voltages and line currents in unbalanced radial electrical distribution networks. IEEE Trans Smart Grid 2013;4:741-70. https://doi.org/10.1109/TSG.2012.2221751.

[202] Conti S, Raiti S, Vagliasindi G. Voltage sensitivity analysis in radial MV distribution networks using constant current models. In: Proceeding of the 2010 IEEE International Symposium Industrial Electronics (ISIE). Italy; July 2010. https://doi.org/10.1109/ISIE.2010.5637545.

[203] Khalid M. Sensitivity matrices for reactive power dispatch and voltage control of large-scale power systems. WSEAS Trans Circuits and Syst 2004;39:1981-23. http://www.wseas.us/elibrary/conferences/izmir2004/papers/489-213.pdf.

[204] Lu Z, Liu J, Liu Y, Ding R, Yang F. The interval sensitivity analysis and optimization of the distribution network parameters considering the load uncertainty. Electrical Power and Energy Systems 2015;64:931-36. https://doi.org/10.1016/j.ijepes.2014.08.022.

[205] Lal NK, Mubeen SE. Voltage dependent load in power flow analysis. Electrical and Electronics Engineering J 2015;2:1-13. https://wireilla.com/engg/eeeij/papers/4215elelij06.pdf.

[206] Shi W, Li N, Xie X, Chu CC, Gadh R. Optimal residential demand response in distribution networks. IEEE J Selected Areas in Communications 2014;32:1441-50. https://doi.org/10.1109/JSAC.2014.2332131. 
[207] Davoudi M. Sensitivity analysis of power system state estimation regarding to network parameter uncertainties. Italy: Ph.D. dissertation in Electrical Engineering Dept Politecnico Di Milano Uni; 2012. https://www.politesi.polimi.it/bitstream/10589/56834/1/2012_03_PhD_Davoudi.pdf.

[208] Petinrin JO, Shaaban M. Voltage control in a smart distribution network using demand response. In: Proceeding of the 2014 IEEE International Conferance Power and Energy (PECon). Malaysia; December 2014. https://doi.org/10.1109/PECON.2014.7062464.

[209] Rahiman FA, Zeineldin HH, Khadkikar V, Kenne SW. Demand response mismatch (DRM): Concept, impact analysis, and solution. IEEE Trans smart grid 2014;5:1734-43. https://doi.org/10.1109/TSG.2014.2309995.

[210] Jamali A, Aghaei J, Esmaili M, Niknam T, Nikoon A. Self-scheduling approach to coordinating wind power producers with energy storage and demand response. IEEE Trans Sust Energ (Early Access) 2019. https://doi.org/10.1109/TSTE.2019.2920884.

[211] Soumya P, Swarup KS. Reliability improvement considering reactive power aspects in a smart grid with Demand Side Management. In: Proceeding of the 2016 IEEE National Power Systems Conference (NPSC). India; Decemaber 2016. https://doi.org/10.1109/NPSC.2016.7858920.

[212] Hirscha A, Parag Y, Guerrero J. Microgrids: A review of technologies, key drivers, and outstanding issues. Renew and Sust Energ Rev J 2018;90:402-11. https://doi.org/10.1016/j.rser.2018.03.040.

[213] Eddy YSF, Gooi HB. Chen SX. Multi-agent system for distributed management of microgrids. IEEE Trans Power Syst 2015;30:24-34. https://doi.org/10.1109/TPWRS.2014.2322622.

[214] Nwulu NL, Xia X. Optimal dispatch for a microgrid incorporating renewables and demand response. Renew Energ J 2017;101:16-28. https://doi.org/10.1016/j.renene.2016.08.026.

[215] Arefifar SA, Ordonez M, Mohamed YARI. Energy management in multi-microgrid systemsDevelopment and assessment. IEEE Trans Power syst 2017;32:910-22. https://doi.org/10.1109/TPWRS.2016.2568858.

[216] Mohsenzadeh A, Pang C, Haghifam MR. Determining optimal forming of flexible microgrids in the presence of demand response in smart distribution system. IEEE Syst J 2018;12:3315-23. https://doi.org/10.1109/JSYST.2017.2739640.

[217] Yang X, Zhang Y, He H, Ren S, Weng G. Real-time demand side management for a microgrid considering uncertainties. IEEE Trans Smart Grid 2019;10:3401-14. https://doi.org/10.1109/TSG.2018.2825388.

[218] Baghaee HR, Mirsalim M, Gharehpetian GB, Talebi HA. Three-phase AC/DC power-flow for balanced/unbalanced microgrids including wind/solar, droop-controlled and electronically-coupled droop-controlled and electronically-coupled basis function neural networks. IET Power Electronics J 2017;10:313-28. https://doi.org/10.1049/iet-pel.2016.0010.

[219] Baghaee HR, Mirsalim M, Sanjari MJ, Gharehpetian GB. Effect of type and interconnection of DG units in the fault level of distribution networks. In: Proceeding of the $13^{\text {th }}$ IEEE Power Electr Motion Control. Poland; 2008. https://doi.org/10.1109/EPEPEMC.2008.4635284.

[220] Baghaee HR, Mirsalim M, Gharehpetian GB. Real-time verification of new controller to improve small/large-signal stability and faultride-through capability of multi-DER microgrids. IET Gener Transm Distrib 2016;10:3068-84. https://doi.org/10.1049/iet-gtd.2016.0315.

[221] Baghaee HR, Mirsalim M, Gharehpetian GB, Talebi HA. Fuzzy unscented transform for uncertainty quantification of correlated wind/PV microgrids: Possibilistic-probabilistic power flow based on RBFNNs. IET Renew. Power Gener 2016;11:867-77. https://doi.org/10.1049/iet-rpg.2016.0669.

[222] Baghaee HR, Mirsalim M, Gharehpetian GB, Talebi A. Application of RBF neural networks and unscented transformation in probabilistic power-flow of microgrids including correlated wind/PV units and plug-in hybrid electric vehicles. Simul Model Pract Theory 2017;72:51-68. https://doi.org/10.1016/j.simpat.2016.12.006.

[223] Etemadi AH, Davison EJ, Iravani R. A generalized decentralized robust control of islanded microgrids. IEEE Trans Power Syst 2014;29:3102-13. https://doi.org/10.1109/TPWRS.2014.2312615.

[224] Baghaee HR, Mirsalim M, Sanjari MJ, Gharehpetian GB. Fault current reduction in distribution systems with distributed generation units by a new dual functional series compensator. In: Procceding of the 13th IEEE Power Electr Motion Control Conference. Poland; September 2008. https://doi.org/10.1109/EPEPEMC.2008.4635357. 
[225] Baghaee HR, Mirsalim M, Gharehpetian GB, Talebi A. A new current limiting strategy and fault model to improve fault ridethrough capability of inverter interfaced DERs in autonomous microgrids. Sustain Energ Technol Ass 2017;24:71-81. https://doi.org/10.1016/j.seta.2017.02.004.

[226] Baghaee HR, Mirsalim M, Gharehpetian GB, Talebi A. Eigenvalue, robustness and time delay analysis of hierarchical control scheme in multi-DER microgrid to enhance small/large-signal stability using complementary loop and fuzzy logic controller. J Circuits Syst Comput 2013;26:134. https://doi.org/10.1142/S0218126617500992.

[227] Babazadeh M, Karimi H. A robust two-degree-of-freedom control strategy for an islanded microgrid. IEEE Trans Power Del 2013;28:1339-47. https://doi.org/10.1109/TPWRD.2013.2254138.

[228] Guerrero JM, Hang L, Uceda J. Control of distributed uninterruptible power supply systems. IEEE Trans. Ind. Electron 2008;55:2845-59. https://doi.org/10.1109/TIE.2008.924173.

[229] Karimi H, Davison EJ, Iravani R. Multivariable servomechanism controller for autonomous operation of a distributed generation unit: Design and performance evaluation. IEEE Trans Power Syst 2010;25:853-65. https://doi.org/10.1109/TPWRS.2009.2031441.

[230] Divshali PH, Alimardani A, Hosseinian SH, Abedi M. Decentralized cooperative control strategy of microsources for stabilizing autonomous VSC-based microgrids. IEEE Trans Power Syst 2012; 27:1949-59. https://doi.org/10.1109/TPWRS.2012.2188914.

[231] Baghaee HR, Mirsalim M, Gharehpetian GB. Performance improvement of multi-DER microgrid for small and large-signal disturbances and nonlinear loads: Novel complementary control loop and fuzzy controller in a hierarchical droop-based control scheme. IEEE Syst J 2018;12:444-51. https://doi.org/10.1109/JSYST.2016.2580617.

[232] Baghaee HR, Mirsalim M, Gharehpetian GB, Talebi HA. A decentralized robust Mixed H2/Ho voltage control scheme to improve small/large-signal stability and FRT capability of islanded multiDER microgrid considering load disturbances. IEEE Syst J 2018;12:2610-21. https://doi.org/10.1109/JSYST.2017.2716351.

[233] Baghaee HR, Mirsalim M, Gharehpetian GB, Talebi HA. MOPSO/FDMT-based Pareto-optimal solution for coordination of overcurrent relays in interconnected networks and multi-DER microgrids. IET Gener Transm Distrib 2018;12:2871-86. https://doi.org/10.1049/iet-gtd.2018.0079.

[234] Dufo-López R, Bernal-Agustín JL. Multi-objective Design of PV-Wind-Diesel-Hydrogen-Battery Systems. Renewable Energy J 2008;33:2559-72. https://doi.org/10.1016/j.renene.2008.02.027.

[235] Kaabeche A, Velhamel M, Ibtiouen R. Sizing Optimization of Grid-Independent Hybrid Photovoltaic/Wind Power Generation System. Energy J 2011;36:1214-22. https://doi.org/10.1016/j.energy.2010.11.024.

[236] Perera ATD, Attalage RA, Perera KKCK, Dassanayake VPC. A Hybrid Tool to Combine MultiObjective Optimization and Multi-Criterion Decision Making in Designing Standalone Hybrid Energy Systems. Appl Energy 2013;107:412-25. https://doi.org/10.1016/j.apenergy.2013.02.049.

[237] Ren H, Zhou W, Nakagami K, Gao W, Wu Q. Multi-Objective Optimization for the Operation of Distributed Energy Systems Considering Economic and Environmental Aspects. Appl Energy 2010;87:3642-51. https://doi.org/10.1016/j.apenergy.2010.06.013.

[238] A Kaviani, Baghaee HR, Riahy GH. Optimal Sizing of a Stand-alone Wind/Photovoltaic Generation Unit using Particle Swarm Optimization. Simulations J 2009;85:89-99. https://doi.org/10.1177\%2F0037549708101181.

[239] Baghaee HR, Mirsalim M, Gharehpetian GB, Talebi A. Reliability/Cost-based Multi-Objective Pareto Optimal Design of Stand-Alone Wind/PV/FC Generation Microgrid System. Energy J 2016;115:1022-41. https://doi.org/10.1016/j.energy.2016.09.007.

[240] Baghaee HR, Mirsalim M, Gharehpetian GB, Kaviani A. Security/Cost-based Optimal Allocation of Multi-Type FACTS Devices Using Multi-Objective Particle Swarm Optimization. Simu Trans Society for Modeling and Simulation Int J 2012;88:999-1010. https://doi.org/10.1177\%2F0037549712438715.

[241] Baghaee HR, Mirsalim M, Gharehpetian GB, Talebi HA. Generalized three phase robust load-flow for radial and meshed power systems with and without uncertainty in energy resources using dynamic radial basis functions neural networks. J Cleaner Production 2018;174:96-113. https://doi.org/10.1016/j.jclepro.2017.10.316. 
[242] Baghaee HR, Mirsalim M, Gharehpetian GB. Power calculation using RBF neural networks to improve power sharing of hierarchical control scheme in multi-DER microgrids. IEEE J Emerging and Selected Topic in Power Electronics 2016;4:1217-25.

https://doi.org/10.1109/JESTPE.2016.2581762.

[243] Baghaee HR, Mirsalim M, Gharehpetian GB, Talebi A. Unbalanced harmonic power sharing and voltage compensation of microgrids using RBFNN-based harmonic power-flow calculations for distributed and decentralized control structures. IET Gener Transm Distr 2018;12:1518-30. https://doi.org/10.1049/iet-gtd.2016.1277.

[244] Regen. Rough guide to engaging communities in energy network innovation. UK; 2017. https://www.regen.co.uk/publications/rough-guide-to-engaging-communities-in-energy-networkinnovation. [Accessed 22 February 2020].

[245] Department for Energy and Climate Change. Demand Side Response in the domestic sector: a literature review of major trials. London: Frontier Economics and Sustainability First; 2012. https://assets.publishing.service.gov.uk/government/uploads/system/uploads/attachment_data/file/4 8552/5756-demand-side-response-in-the-domestic-sector-a-lit.pdf.

[246] Raw G, Ross D. Energy Demand Research Project: Final Analysis. AECOM Limited. UK; June 2011. https://www.ofgem.gov.uk/ofgem-publications/59105/energy-demand-research-project-finalanalysis.pdf.

[247] Office of Gas and Electricity Markets (Ofgem). Energy Demand Research Project; 2010. https://www.ofgem.gov.uk/gas/retail-market/metering/transition-smart-meters/energy-demandresearch-project.

[248] Commision of Energy Regulation (CER). Electricity smart metering technology trials findings report. Ireland; May 2011. https://www.cru.ie/wp-content/uploads/2011/07/cer11080ai.pdf.

[249] Northern Powergrid (Northeast) Limited. Customer-led network revolution; 2015. http://www.networkrevolution.co.uk. [Accessed 10 January 2020].

[250] Bulkeley H, Matthews P, Whitaker G, Bell S, Wardle R, Lyon S, Powells G. High level summary of learning: Domestic Smart Meter Customers on Time of Use Tariff Customer Lead Network Revolution project. Northern Power Grid; 2015. http://www.networkrevolution.co.uk/wpcontent/uploads/2015/01/CLNR-L243-High-Level-Summary-of-Learning-Domestic-Smart-MeterCustomers-on-Time-of-Use-Tariffs.pdf.

[251] Western Power Distribution. Energy control for household optimisation- closedown report; December 2016. file:///D:/Users/davar1s/Downloads/ECHO-Close-Down-FINAL\%20(1).pdf.

[252] Western Power Distribution and Regen SW. Sunshine tariff- summary report; 2017. https://www.westernpower.co.uk/downloads/5396. [Accessed 22 February 2020].

[253] UK Power Networks and Low Carbon London Learning Lab. DNO guide to future smart management of distribution network; 2014. https://innovation.ukpowernetworks.co.uk/wpcontent/uploads/2019/05/Summary-Report.pdf [Accessed 22 February 2020].

[254] Electricity North West. Customer Load active system services second tier LCN fund addendum to project closedown report; 2016. https://www.enwl.co.uk/globalassets/innovation/class/classdocuments/class-extension---addendum-to-closedown-report-v2.pdf [Accessed 22 February 2020].

[255] Office of Gas and Electricity Markets (Ofgem). Shetland northern isles new energy solutions (NINES) project consultation; 2011. https://www.ofgem.gov.uk/ofgempublications/43538/shepdninesconsultation.pdf. [Accessed 22 February 2020].

[256] SP Energy Networks. Accelerating renewable connections (ARC) closedown report; 2017. https://www.spenergynetworks.co.uk/userfiles/file/ARC_Closedown_Report.pdf. [Accessed 22 February 2020].

[257] Western Power Distribution. Smart energy Isles, closedown project; 2016. https://www.westernpower.co.uk/downloads/2470. [Accessed 22 February 2020].

[258] Western Power Distribution. Project sola Bristol; 2018. https://www.westernpower.co.uk/innovation/projects/smart-energy-isles. [Accessed 25 February 2020].

[259] EA Technology \& Southern Electric Power Distribution (SEPD). SSET205 - my electric avenue (I2EV), project close-down report; 2016. https://www.ofgem.gov.uk/ofgem-publications/100342. [Accessed 22 February 2020]. 
[260] UK Power Networks. Energywise-the final energy saving trial report; 2016. https://innovation.ukpowernetworks.co.uk/wp-content/uploads/2019/05/Energywise-The-FinalEnergy-Saving-Trial-Report.pdf. [Accessed 22 February 2020].

[261] Scottish and Southern Electricity Networks. SAVE-Solent achieving value from efficiency; 2016. https://www.ssepd.co.uk/save. [Accessed 22 February 2020].

[262] Northern Power Grid. Activating community engagement customer engagement plan; 2015. https://www.northernpowergrid.com/ACE. [Accessed 19 January 2020].

[263] Electricity Northern West. Power saver challenge project closedown report; 2017. https://www.enwl.co.uk/globalassets/innovation/power-saver-challenge/power-saver-challengeclosedown-report.pdf. [Accessed 22 February 2020].

[264] Coxcoon R, Sansom H, McMullen J, Ballard C. Community energy action (less is more). Western Power Distribution via Ofgem; January 2015. https://www.cse.org.uk/downloads/reports-andpublications/community-energy/energy-advice/behaviour-change/community-energy-actionreport.pdf.

[265] Baloglu UB, Demir Y. A bayesian game-theoretic demand response model for the smart grid. Smart Grid and Clean Energy 2015;4:132-38. https://pdfs.semanticscholar.org/ae5f/f399cbff22c0c7759f0c157459cb2a7ba915.pdf.

[266] BBC News. Smart meter rollout delayed for four years; 2019. https://www.bbc.co.uk/news/business-49721436. [Accessed 25 July 2020].

[267] Smart Meters. Technical information; 2020. https://www.smartme.co.uk/technical.html\#gsc.tab=0. [Accessed 25 July 2020].

[268] The Telegraph. Households saying no to smart meters will mean deadline is missed, says report; 2019. https://www.telegraph.co.uk/news/2019/11/14/households-saying-no-smart-meters-willmean-deadline-missed. [Accessed 25 July 2020].

[269] Energy Live News. Proposed target of deploying smart meters to $85 \%$ of homes by 2024 'is impossible; 2019.https://www.energylivenews.com/2019/11/15/target-of-deploying-smart-metersto-85-of-homes-by-2024-is-impossible. [Accessed 25 July 2020].

[270] Andonia M, Robu V, Flynn D, Abram S, Geach D, Jenkins D, McCallum P, Peacock A. Blockchain technology in the energy sector: A systematic review of challenges and opportunities. Renew Sust Energ Rev 2019;100:143-74. https://doi.org/10.1016/j.rser.2018.10.014.

[271] Blyth W, McCarthy R, Gross R. Financing the UK Power Sector: Is the Money Available?. Energy Policy 25015;87:607-22. https://www.biee.org/wpcms/wp-content/uploads/Blyth-Financing-theUK-Power-Sector-BIEE.pdf.

[272] Eid C, EltaKoliou M, Mercedes V, Reneses J, Hakvoort R. Time-based pricing and electricity demand response: Existing barriers and next steps. Utilities Policy J 2015;40:15-25. https://doi.org/10.1016/j.jup.2016.04.001.

[273] Hakvoort R, Koliou E. Energy management and demand side response. Energy Science and Technology. Studium Press LLC; 2014.

[274] Paterakis NG, Tascikaraoglu A, Erdinc O, Bakirtzis AG, Catalao JPS. Assessment of demandresponse-driven load pattern Elasticity using a combined approach for smart households. IEEE Trans Industrial Informatics 2016;12:1529-39. https://doi.org/10.1109/TII.2016.2585122.

[275] Scott P, Thiebaux S, Briel MVD, Hentenryck PV. Residential demand response under uncertainty. In: Proceeding of the International Cpnference Principles and Practice of Constraint Programming. Heidelberg; 2013. https://users.cecs.anu.edu.au/ thiebaux/papers/greencoplas13.pdf.

[276] Qayyum FA, Naeem M, Khwaja A, Anpalagan A, Guan L, Venkatesh B. Appliance Scheduling Optimization in Smart Home Networks. IEEE Access 2015;3:2176-90. https://doi.org/10.1109/ACCESS.2015.2496117.

[277] Roh H, Lee W. Residential Demand Response Scheduling With Multiclass Appliances in the Smart Grid. IEEE Trans Smart Grid 2016;7:94-104. https://doi.org/10.1109/TSG.2015.2445491.

[278] Chen Z, Wu L, Fu Y. Real-Time Price-Based Demand Response Management for Residential Appliances via Stochastic Optimization and Robust Optimization. IEEE Trans Smart Grid 2012;3:1822-31. https://doi.org/10.1109/TSG.2012.2212729.

[279] Tsui KM, Chan SC. Demand Response Optimization for Smart Home Scheduling Under Real-Time Pricing. IEEE Trans Smart Grid 2012;3:1812-21. https://doi.org/10.1109/TSG.2012.2218835. 
[280] Du P, Lu N. Appliance Commitment for Household Load Scheduling. IEEE Trans Smart Grid 2011;2:411-19. https://doi.org/10.1109/TSG.2011.2140344.

[281] Pal S, Kumar R. Effective load scheduling of residential consumers based on dynamic pricing with price prediction capabilities. In: Proceeding of the 1st IEEE International Conference Power Electronics in Intelligent Control and Energy Systems (ICPEICES). India; 2016. https://doi.org/10.1109/ICPEICES.2016.7853245.

[282] Zhang D, Li S, Sun M, O’Neill Z. An Optimal and Learning-Based Demand Response and Home Energy Management System. IEEE Trans Smart Grid 2016;7:1790-801. https://doi.org/10.1109/TSG.2016.2552169.

[283] Ozturkr Y, Senthilkumar D, Kumar S, Lee G. An Intelligent Home Energy Management System to Improve Demand Response. IEEE Trans Smart Grid 2013;4:694-701. https://doi.org/10.1109/TSG.2012.2235088. 